Universidade de São Paulo

Faculdade de Filosofia, Ciências e Letras de Ribeirão Preto

Programa de Pós-Graduação em Psicobiologia

\title{
ORGANIZAÇÃO DO SISTEMA NEURAL MESENCEFÁLICO RESPONSÁVEL PELA RESPOSTA DE CONGELAMENTO
}

Daniel Machado Luiz Vianna

Tese apresentada à Faculdade de Filosofia, Ciências e Letras de Ribeirão Preto - USP, como parte das exigências para a obtenção do título de Doutor em Ciências, Área de Psicobiologia. 


\title{
ORGANIZAÇÃO DO SISTEMA NEURAL MESENCEFÁLICO RESPONSÁVEL PELA RESPOSTA DE CONGELAMENTO
}

\author{
Daniel Machado Luiz Vianna
}

Tese apresentada à Faculdade de Filosofia, Ciências e Letras de Ribeirão Preto - USP, como parte das exigências para a obtenção do título de Doutor em Ciências, Área de Psicobiologia.

Orientador: Prof. Dr. Marcus Lira Brandão 


\section{SUMÁRIO}

\section{INTRODUÇÃO}

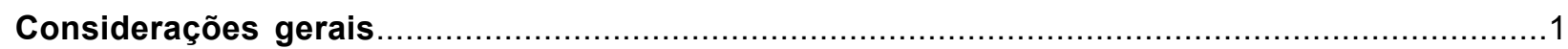

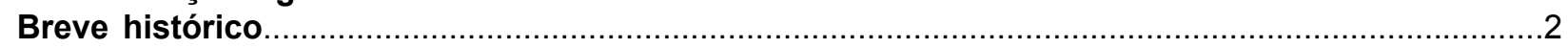

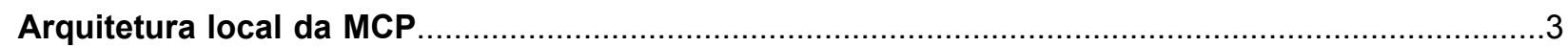

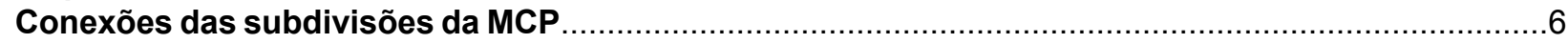

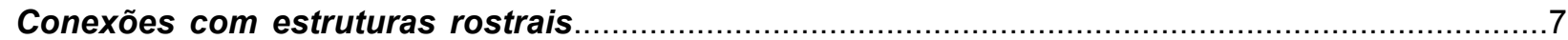

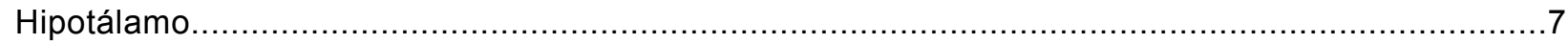

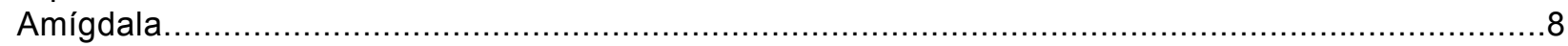

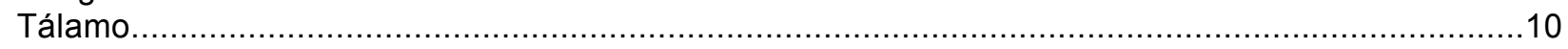

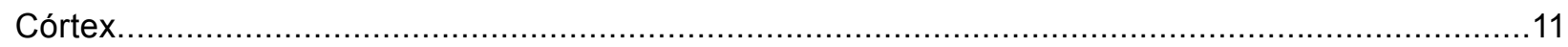

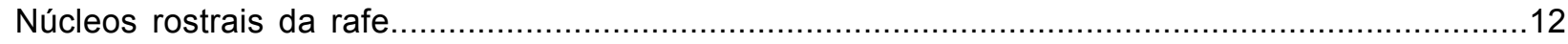

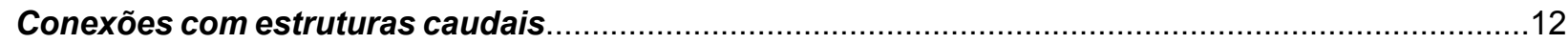

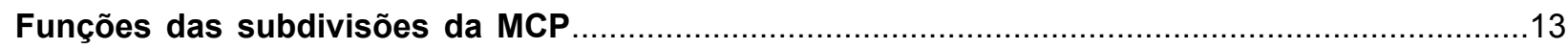

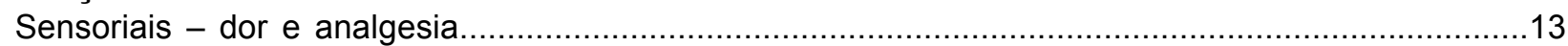

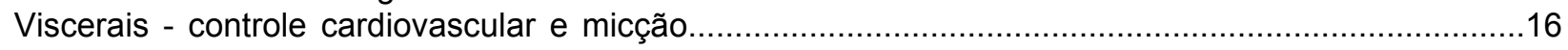

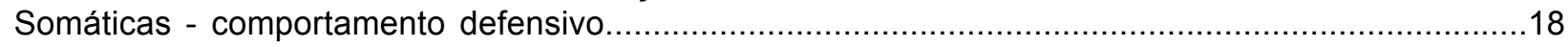

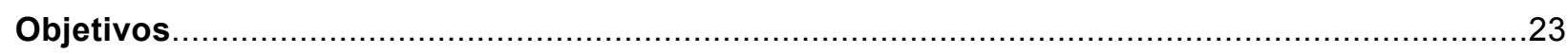

MÉTODOS

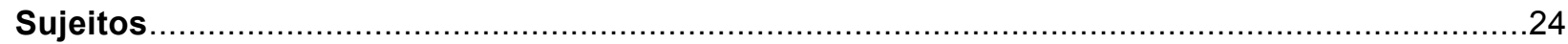

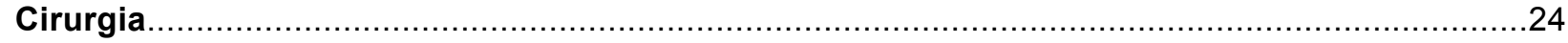

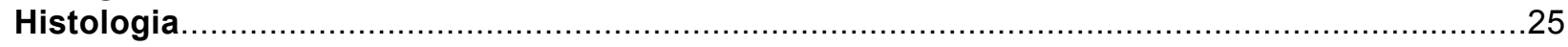

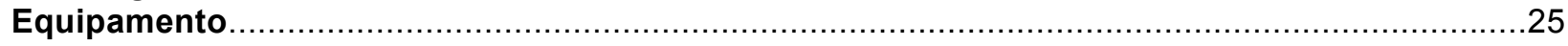

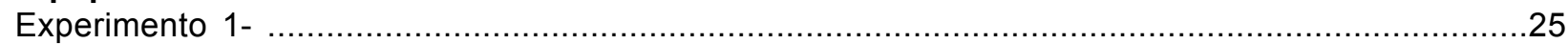

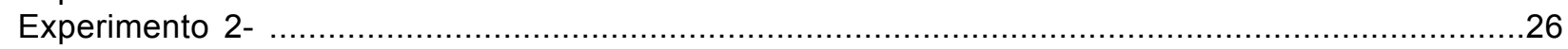

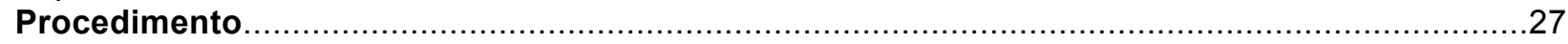

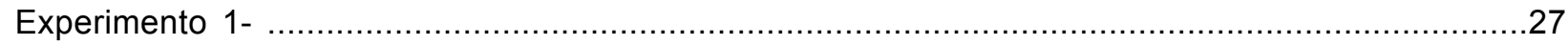

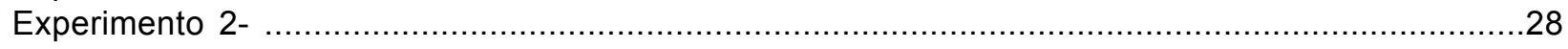

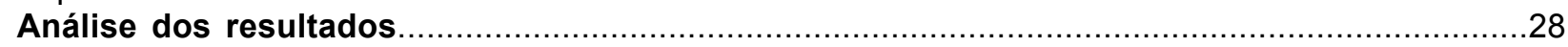

\section{RESULTADOS}

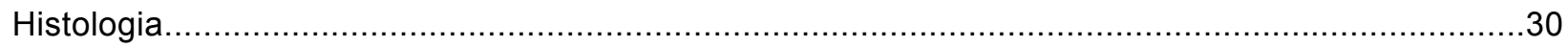

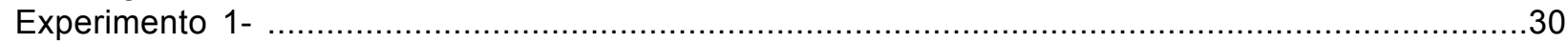

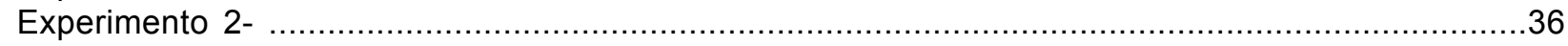

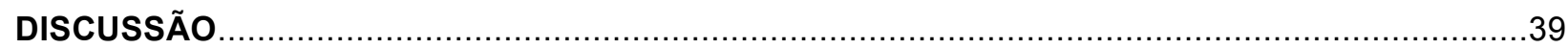

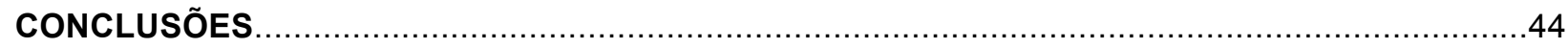

RESUMO

ABSTRACT T

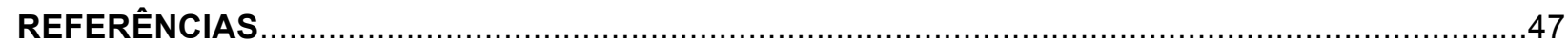




\section{ABREVIATURAS}

CeA: núcleo central da amígdala

CnF: núcleo cuneiforme

DR: núcleo dorsal da rafe

GABA: ácido $\gamma$-aminobutírico

HM: hipotálamo medial

MCP: matéria cinzenta periaquedutal

MCPdl: matéria cinzenta periaquedutal dorsolateral

MCPdm: matéria cinzenta periaquedutal dorsomedial

MCPI: matéria cinzenta periaquedutal lateral

MCPvl: matéria cinzenta periaquedutal ventrolateral

MnR: núcleo mediano da rafe

NAH: núcleo anterior do hipotálamo

PMd: núcleo pré-mamilar dorsal

RNAm: RNA mensageiro

SNC: sistema nervoso central 
If a man will begin with certainties, he shall end in doubts; but if he will be content to begin with doubts, he shall end in certainties.

Francis Bacon, Advancement of Learning 


\section{Agradecimentos}

Ao Prof. Dr. Marcus Lira Brandão, que deu crédito ao meu trabalho. 


\section{Mais Agradecimentos}

À Dona Lola e Nete, as mães, à primeira por ser severa quando eu relaxo, e à segunda por me mimar.

Aos colegas do laboratório, que não serão nomeados. O motivo eu esqueci.

Aos professores Newton S. Canteras e Luiz Carlos Schenberg, que me receberam em seus laboratórios, escutaram minhas dúvidas e dividiram comigo seus macetes.

Aos professores estrangeiros que visitaram o laboratório durante este período.

Às secretárias, técnicos e auxiliares de serviços gerais do departamento.

À Fá.

Ao Sérgio.

Ao CNPq, pelo apoio financeiro.

E a todos os que ficaram subentendidos, claro! 
Introdução 


\section{Considerações gerais}

Todos os seres vivos são fonte de nutrientes para outros seres vivos, o que os tornam presas em potencial. Os que são incapazes de se defender são eliminados. Os descendentes dos que restam herdam as características que permitiram a sobrevivência de seus genitores. Embora semelhantes a estes, os descendentes também variam em sua capacidade de se defender de predadores. Os menos capazes serão novamente eliminados, e os que restarem passarão as características que permitiram sua sobrevivência aos seus descendentes.

A variação que ocorre nos descendentes muitas vezes inclui novidades que não estavam presentes nos seus genitores, o que permite que, ao longo de grandes períodos de tempo, grandes mudanças ocorram. No caso dos mamíferos, permitiu que regiões específicas de seu sistema nervoso central fossem selecionadas para comandar estratégias de defesa comportamental mais ou menos preestabelecidas, de acordo com o tipo de perigo que se apresentasse.

Ao serem desafiados por uma situação ameaçadora, os animais tendem a reagir de duas maneiras distintas: ou a enfrentam de forma ativa, fugindo ou lutando, ou então de forma passiva, ficando quietos e imóveis. A essa imobilidade que ocorre em face ao perigo chamamos de congelamento. Entretanto, como veremos a seguir, esta única denominação pode ocultar mais de um fenômeno. 


\section{Breve histórico}

A pesquisa da localização do substrato neural dos comportamentos de defesa começou no final do século XIX e início do século XX. Goltz (1892, citado em Bard, 1928) observou que um cão cujos hemisférios cerebrais haviam sido removidos, ainda era capaz de mostrar uma reação de raiva que se assemelhava à de um cão normal. Bard (1928) demonstrou que ablações rostrais ao hipotálamo não afetavam as respostas de defesa comportamentais e vegetativas de gatos acordados. Tais respostas deixavam de ser observadas caso essa estrutura fosse removida. Magoun, Atlas, Ingersoll \& Ranson (1937), por meio de estimulação elétrica, conseguiram observar respostas vocais e vegetativas de defesa evocadas de uma região ainda mais caudal, a matéria cinzenta periaquedutal (MCP), no gato imobilizado. Utilizando uma técnica que possibilitava a estimulação intracraniana de animais não restritos, Hess \& Brügger (1943), estimularam a região perifornical do hipotálamo de gatos não restritos, observando nos animais comportamentos de defesa semelhantes aos apresentados em resposta a estímulos ameaçadores, como aqueles representados por um predador. Reações semelhantes foram também conseguidas com a estimulação da MCP (Hunsperger, 1956). Comportamentos similares foram observados após a microinjeção de carbacol (Baxter, 1968) e aminoácidos excitatórios, que estimulam apenas corpos neuroniais e não fibras de passagem (Bandler e cols., 1985).

Estudos de lesão foram consistentes com esses achados. Reações de defesa podem ser provocadas pela estimulação elétrica ou química de várias áreas do sistema nervoso central, dentre elas a amígdala, o hipotálamo medial e a MCP dorsal (Graeff, 1994). Entretanto, a MCP é considerada a estrutura mais crítica para a expressão dos comporta- 
mentos de defesa, já que é o único sítio cuja lesão abole os efeitos da estimulação das áreas citadas, sendo este déficit permanente (Hunsperger, 1963). Já o contrário não se verifica, pois nem a ablação do telencéfalo (Tomaz et al., 1988) nem a lesão do hipotálamo medial ou posterior (Hunsperger, 1963) têm efeito sobre as reações de defesa provocadas na MCP. A lesão da MCP reduz drasticamente ou elimina os comportamentos de defesa inatos (Blanchard et al., 1981) e aprendidos (LeDoux et al., 1988). Tais achados têm levado alguns autores a propor a MCP como a "via final comum" para os comportamentos de defesa (Bandler, 1987).

\section{Arquitetura local da MCP}

Inicialmente a MCP era considerada uma estrutura unitária, com grande variedade celular, mas sem fronteiras anatômicas claras que pudessem sugerir a presença de subnúcleos ou subregiões com especialização funcional (Mantyh, 1982a). A organização das projeções também sugeria pouca variação regional (Mantyh, 1982b, 1983a,b).

Muitos fatores complicam a identificação de subregiões anatômicas na MCP. Os neurônios são pequenos ou médios, muito compactados e sem células gliais intercalandoos. Há uma grande profusão de axônios finos sem mielina, orientados longitudinalmente, especialmente na região pobre em células que cerca o aqueduto cerebral. Os axônios possuem muitas sinapses e varicosidades. Os dendritos não possuem espinhas sinápticas, e em geral são direcionados ao aqueduto (Buma et al., 1992). Ou seja, afora a orientação longitudinal do sistema, é muito difícil discernir o que se conecta com o quê.

Alvin Beitz (1985) foi o primeiro a descrever subdivisões regionais na MCP do rato, 
organizadas longitudinalmente, com base na freqüência de vários aspectos morfológicos. Em seguida, estudos imunohistoquímicos demonstraram que a quimioarquitetura da MCP também não é uniforme, mas apresenta variações regionais mais ou menos coerentes com este modelo.

Neurônios imunorreativos às enzimas sintetizadoras do glutamato (Clements et al., 1987, Fig.1), do aspartato (Clements et al., 1987, Fig.2), do Ácido $\gamma$-aminobutírico (GABA, Barbaresi e Manfrini, 1988, Fig.3) e da acetilcolina (Ruiz-Torner et al., 2001, Fig.4), bem como ao RNAm da encefalina (Smith et al., 1994, Fig.5) e à neurotensina (Shipley et al., 1987, Fig.6) foram encontrados em menor quantidade na MCP dorsolateral (MCPdl) do que nas outras subregiões. A expressão da enzima mitocondrial citocromo-oxidase também é menor na MCPdl (Conti et al., 1988, Fig.7). Por outro lado, a MCPdl possui mais neurônios imunorreativos à enzima sintetizadora do óxido nítrico (Vincent \& Kimura, 1992; Onstott et al., 1993, Fig.8; Ruiz-Torner et al., 2001). Já a subdivisão ventrolateral ao aqueduto (MCPvl) é a única que possui neurônios imunorreativos à serotonina (Clements et al., 1985, Fig.9) e à glicina (Rampon et al., 1996, Fig.10). O RNAm da encefalina, por sua vez, é mais expresso na MCP lateral (MCPI) e dorsomedial (MCPdm; Smith et al., 1994, Fig.5). Finalmente, o RNAm da galanina (Smith et al., 1994, Fig.11) e do polipeptídeo vasoativo intestinal (Smith et al., 1994, Fig12) encontram-se apenas na região mais próxima ao aqueduto, chamada medial (Beitz, 1985) ou juxta-aquedutal (Ruiz-Torner et al., 2001).

Entretanto, nem todos os marcadores químicos têm uma distribuição compatível com este modelo. Exemplos são a substância P e a somatostatina, cujos RNAms são expressos por grupos neuroniais que não respeitam as fronteiras das subregiões. Apesar disso, mesmo estes neurônios estão agrupados em contínuos rostrocaudais (Smith et al., 1994). 


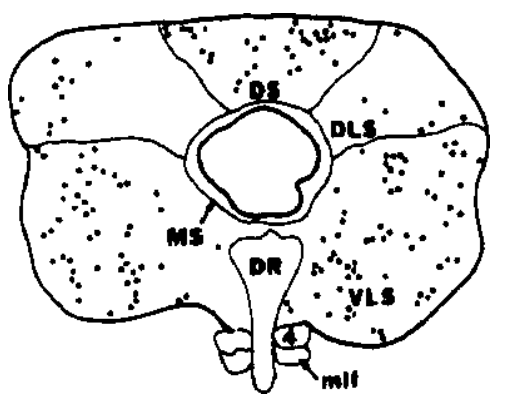

Fig. 1. Neurônios Glutamatérgicos (Clements et al., 1987)

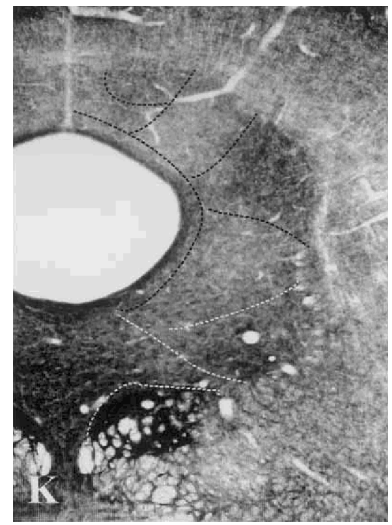

Fig.4. Neurônios colinérgicos (Ruiz-Torner et al., 2001)

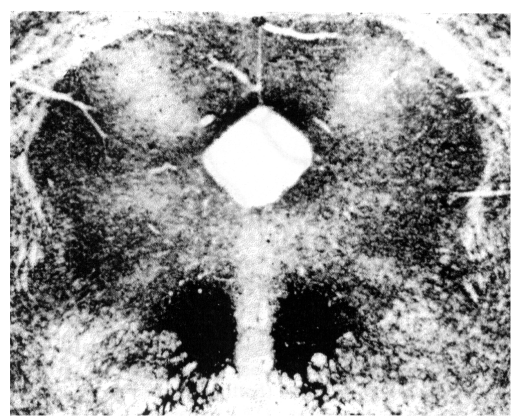

Fig.7. Distribuição da citocromooxidase na MCP (Conti et al., 1988)

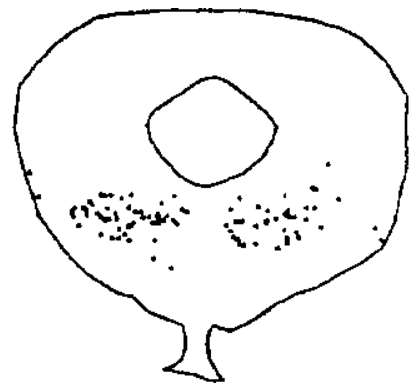

Fig. 10. Neurônios contendo glicina (Rampon et al., 1996)

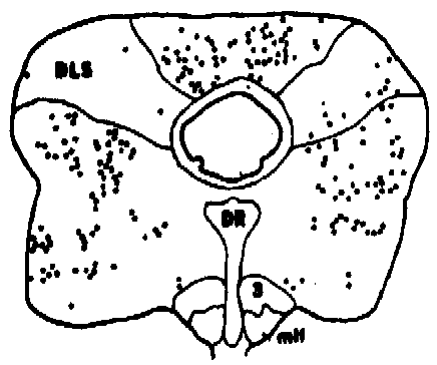

Fig. 2. Neurônios aspartatérgicos (Clements et al., 1987)

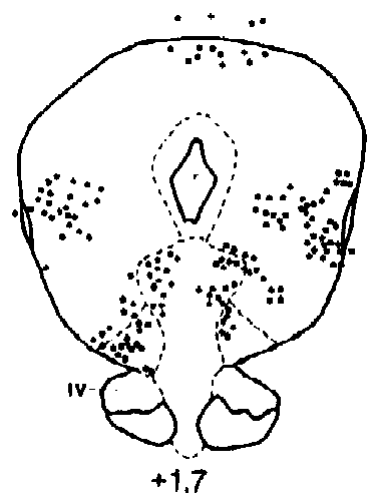

Fig. 5. Neurônios encefalinérgicos (Smith et al., 1994)

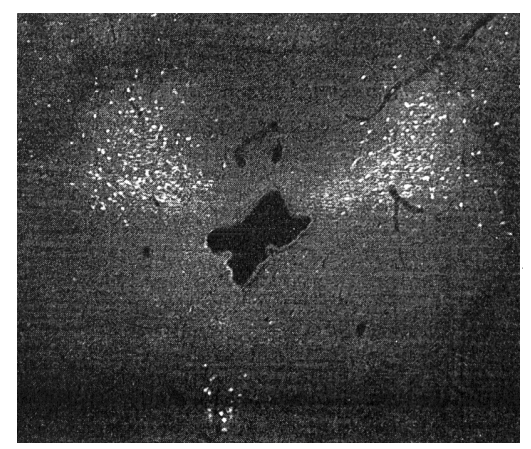

Fig.8. Neurônios nitrérgicos (Onstott et al., 1993)

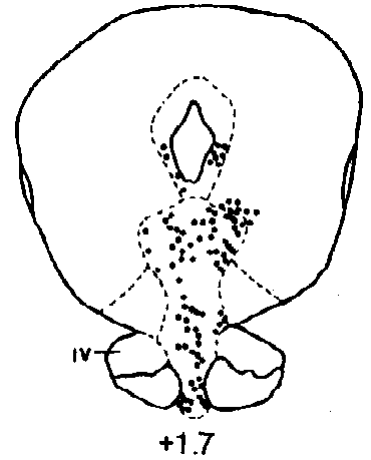

Fig. 11. N. galaninérgicos (Smith et al., 1994)

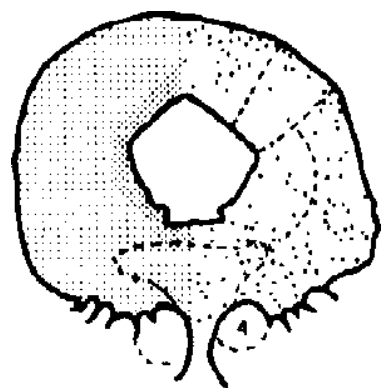

Fig. 3. Neurônios GABAérgicos (Barbaresi \& Manfrini, 1988)

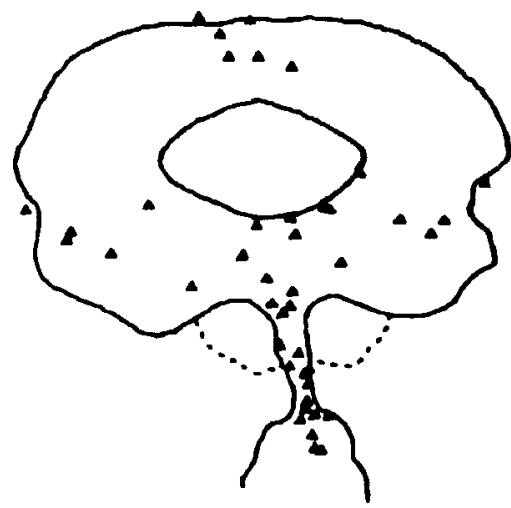

Fig. 6. N. neurotensinérgicos (Shipley et al., 1987)

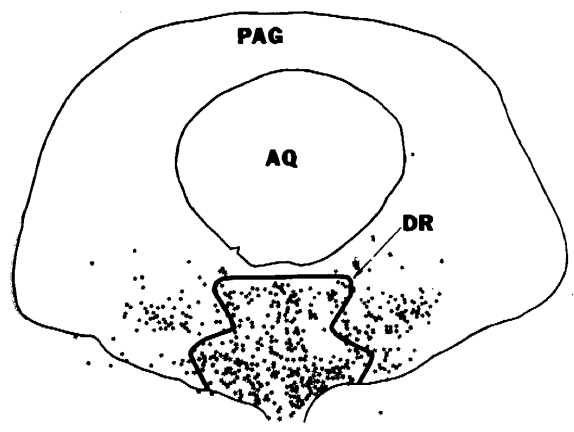

Fig. 9. Neurônios contendo serotonina (Clements et al., 1985)

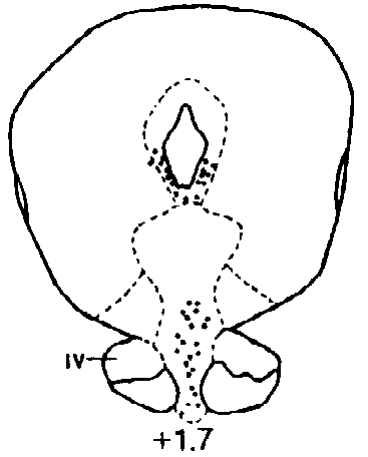

Fig. 12. N. vasopeptidérgicos (Smith et al., 1994)

Figs. 1 a 12: Nestas figuras estão representadas secções coronais típicas da MCP. Nas figuras 4 e 7, áreas escuras indicam imunorreatividade à substância estudada. Na figura 8 , pontos claros indicam células marcadas por imunofluorescência. Nas demais figuras, as células marcadas por hibridização in situ são representadas por pontos pretos. 


\section{Conexões das subdivisões da MCP}

As conexões que a MCP mantém com outras estruturas do sistema nervoso central não são homogêneas em toda sua extensão, sugerindo especializações regionais. Em seguida, apresentamos estruturas que possuem conexões com a MCP, selecionadas por meio de três critérios: a) mantêm conexões monossinápticas densas ou moderadas com a MCP; b) foram implicadas na mediação de reações comportamentais de defesa e c) cujas conexões estão distribuídas desigualmente entre as diversas subdivisões da MCP. Ensaios com ligantes radioativos não foram incluídos nesta revisão, pois consideramos as técnicas de marcação imunohistoquímicas anatomicamente mais precisas. Um sumário dessas conexões pode ser visto na tabela 1.

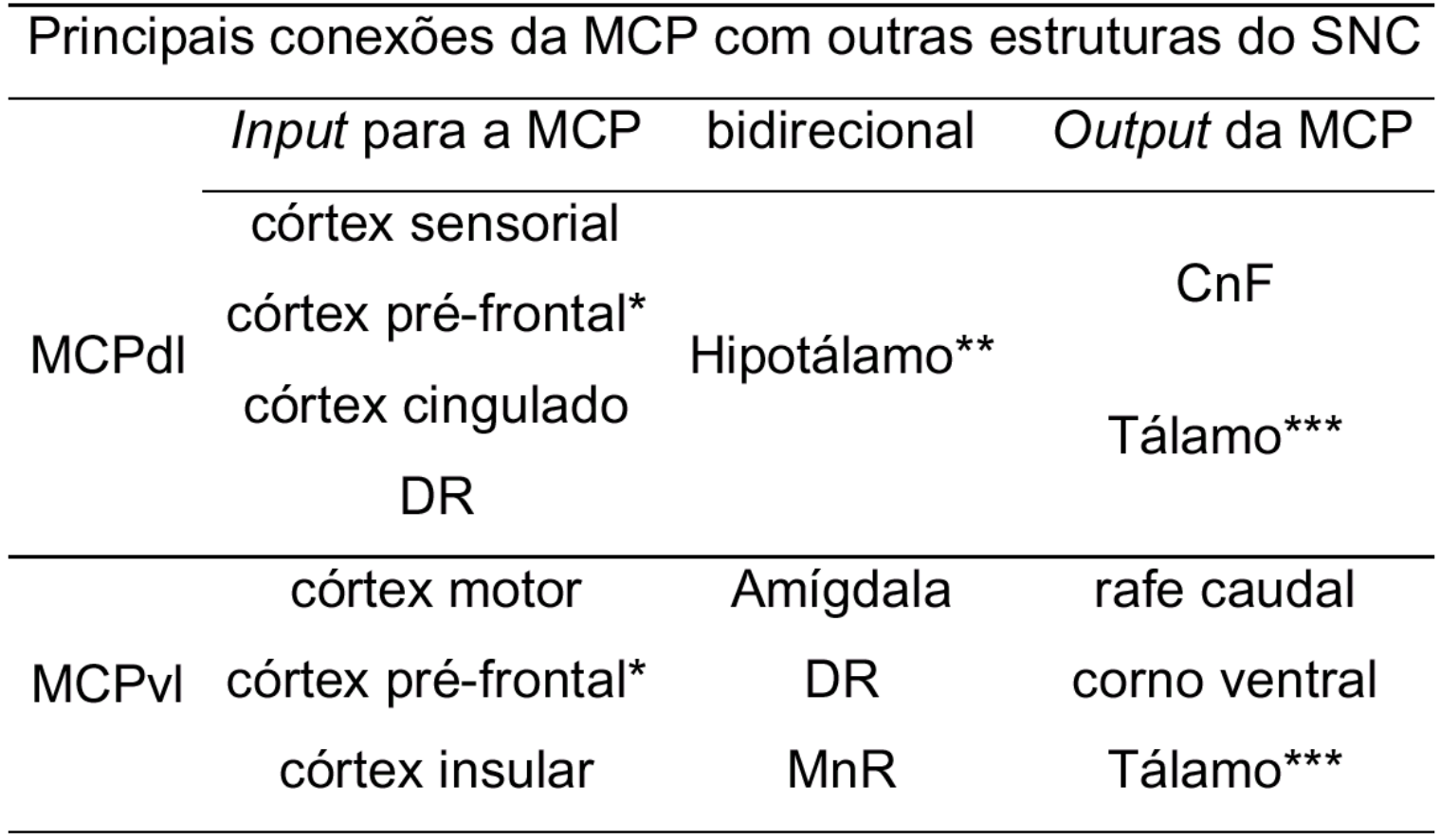

Tabela 1. * regiões distintas projetam preferencialmente para a MCPdl e a MCPvl; ** para um sumário mais detalhado das conexões entre o hipotálamo e a MCP, veja a Fig.14; *** Não há consenso na literatura sobre os domínios preferencialmente inervados pela MCP. Abreviaturas: $\mathrm{CnF}$-núcleo cuneiforme; $\mathrm{DR}$ - núcleo dorsal da rafe; $\mathrm{MCP}$ - matéria cinzenta periaquedutal; $\mathrm{MCPdl}-\mathrm{MCP}$ dorsolateral; $\mathrm{MCPVl}-\mathrm{MCP}$ ventrolateral; $\mathrm{MnR}$ - núcleo mediano da rafe; SNC - sistema nervoso central. 


\section{a) conexões com estruturas rostrais}

Hipotálamo

O hipotálamo é tradicionalmente considerado como um dos principais centros efetores para as reações de defesa viscerais (LeDoux et al., 1988), mas uma longa linha de investigação também aponta sua relevância para a mediação das respostas de defesa comportamentais. Entre as evidências mais importantes está a fuga provocada pela microinjeção de antagonistas do GABA numa área abrangente do hipotálamo medial (HM; Schmitt et al., 1986), um efeito que resiste à ablação do telencéfalo (Tomaz et al., 1988). Entretanto, esta abordagem não foi capaz de definir claramente que núcleos hipotalâmicos mediariam as respostas assim eliciadas.

Mais recentemente, Canteras (2002) chamou a atenção para uma rede de subnúcleos hipotalâmicos que podem influenciar a expressão do comportamento defensivo. Esta rede seria composta pelo núcleo anterior do hipotálamo $(\mathrm{NAH})$, pela região dorsomedial do núcleo ventromedial do hipotálamo (HVM) e pelo núcleo pré-mamilar dorsal (PMd). Lesões químicas atingindo apenas corpos celulares do pólo caudal desta rede (PMd) virtualmente aboliram as respostas de congelamento e fuga que ocorrem durante a exposição a um predador natural (Canteras, 2002). Todos esses núcleos têm expressão Fos aumentada durante a exposição ao odor do predador (Dielenberg et al., 2001) ou após a fuga provocada pela microinjeção de doadores de óxido nítrico na MCPdl (de Oliveira et al., 2000). Outros estudos também sugeriram a participação destas regiões nas respostas provocadas pela estimulação elétrica do HM (Sandner et al., 1993) e da MCP dorsal (Sandner et al., 1992). 
Cameron et al. (1995) compararam as projeções dos neurônios localizados nas porções rostral e caudal da MCPdl e MCPvl. Seus resultados revelam que a dIPAG rostral projeta densamente para o $\mathrm{NAH}$, enquanto que as outras regiões projetam moderadamente (MCPdl caudal) ou fracamente (MCPvl rostral).

O NAH projeta densamente para todas as subdivisões da MCP (Semenenko et al., 1992). Outra densa projeção deste núcleo vai para o HVM, que envia numerosas projeções para a MCPdl rostral (Canteras, 2002). O HVM também projeta para vários núcleos da amígdala, dentre eles o núcleo central (CeA; Canteras, 2002). O NAH tem conexões recíprocas com o PMd, e também uma projeção indireta via HVM (Canteras, 2002). O PMd projeta densamente para a MCPdl (Fig.13A) e MCP rostral, e muito menos para as outras subdivisões da MCP (Canteras \& Swanson, 1992). Em suma, estes núcleos hipotalâmicos mantêm conexões com a MCP preferencialmente através da MCPdl (Fig.14).

Amígdala

A amígdala se comunica com a MCP apenas através do seu núcleo central (CeA). Estas conexões são diretas e recíprocas, e tanto inputs quanto outputs envolvem preferencialmente a MCPvl (Rizvi et al., 1991, Fig.15D). A desativação desta via com lidocaína causa uma redução drástica do congelamento condicionado (Carrive et al., 2000). A única estrutura alvo do CeA cuja lesão tem o mesmo efeito é a MCP caudal (LeDoux et al., 1988). A amígdala medeia o medo condicionado e incondicionado (Vazdarjanova, 2000), mas não o congelamento incondicionado. Sua lesão excitotóxica não muda o congelamento observado imediatamente após o choque nas patas (Antoniadis \& McDonald, 2001), e mesmo o 


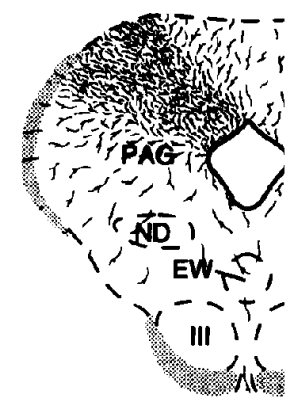

do núcleo premamilar dorsal (Canteras \& Swanson, 1992)

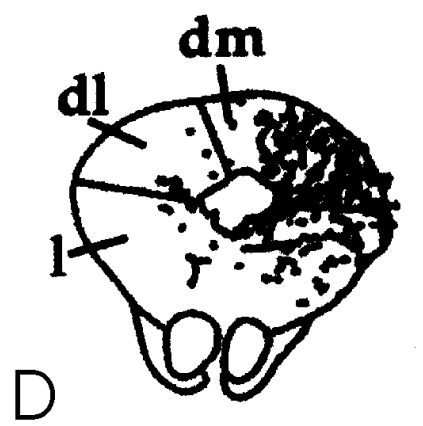

do córtex cingulado anterior (Floyd et al., 2000)

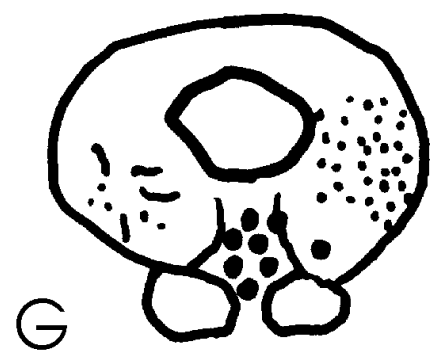

do córtex motor primário (tronco e membros posteriores; Newman et al., 1989)

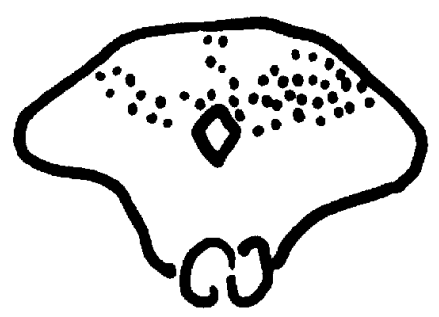

B

do córtex auditivo primário (Newman et al., 1989)

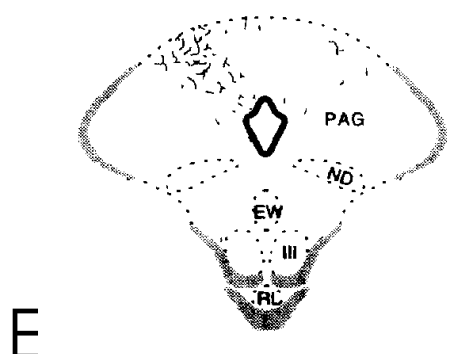

do córtex retrosplenial agranular lateral (Risold et al., 1997)

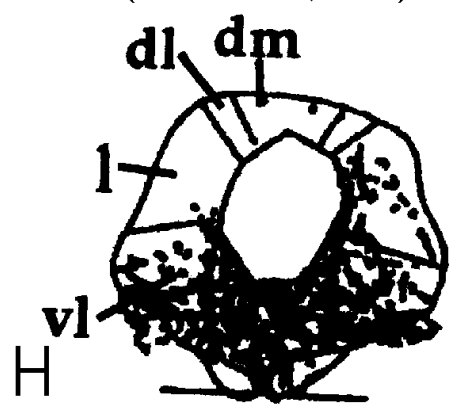

do córtex pré-límbico rostral (Floyd et al., 2000)

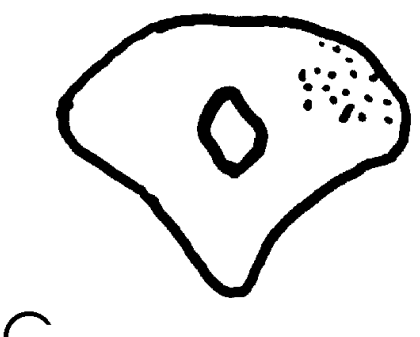

do córtex visual secundário (Newman et al., 1989)

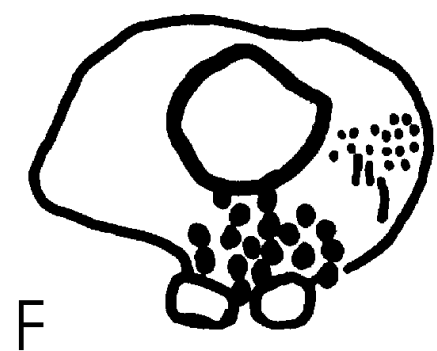

do córtex motor primário (membros dianteiros; Newman et al., 1989)

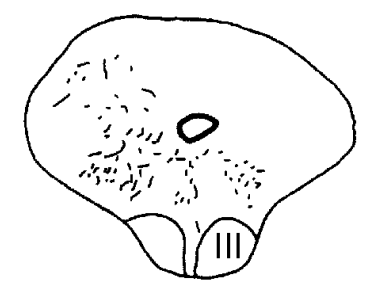

do núcleo dorsal da rafe (Vertes, 1991)

Fig. 13. Localização de terminações de outras regiões do SNC para a MCP. Abreviaturas: dl - dorsolateral; dmdorsomedial; I - lateral;MCP - matéria cinzenta periaquedutal; SNC - sistema nervoso central; vl - ventrolateral.

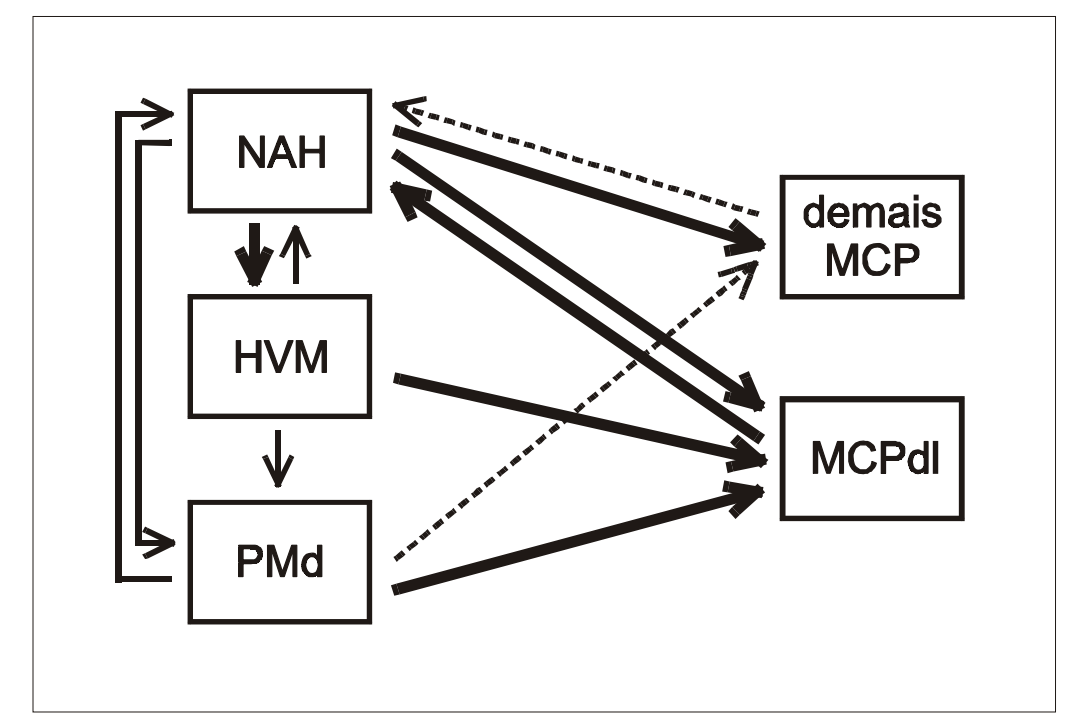

Fig. 14. Principais conexões entre os núcleos hipotalâmicos relacionados ao comportamento de defesa e a MCP. A espessura das setas indica a densidade relativa das projeções. Abreviaturas: demais MCP - todas as subdivisões da MCP exceto a MCPdl; HVM núcleo ventromedial do hipotálamo; NAH - núcleo anterior do hipotálamo; MCP matéria cinzenta periaquedutal; MCPdl - MCP dorsolateral; PMd - núcleo prémamilar dorsal. 


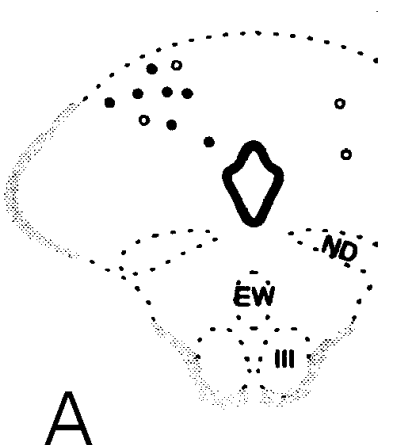

para o núcleo reuniens (Risold et al., 1997)

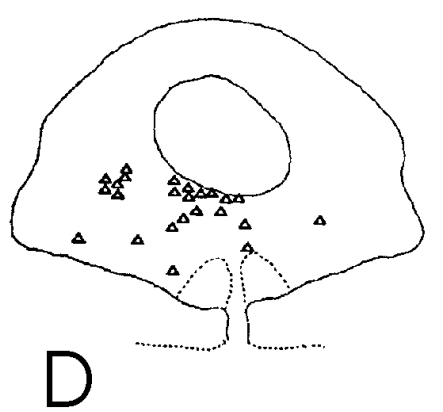

para o núcleo central da amígdala (Rizvi et al., 1991)

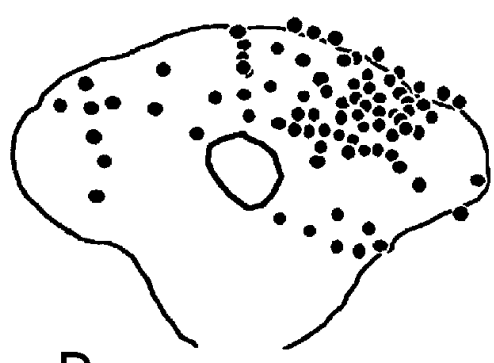

B

para o núcleo cuneiforme (Redgrave et al., 1998)

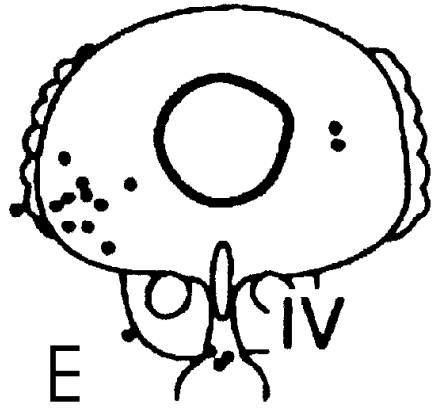

para o corno ventral da medula espinhal (Mouton \& Holstege, 1994)

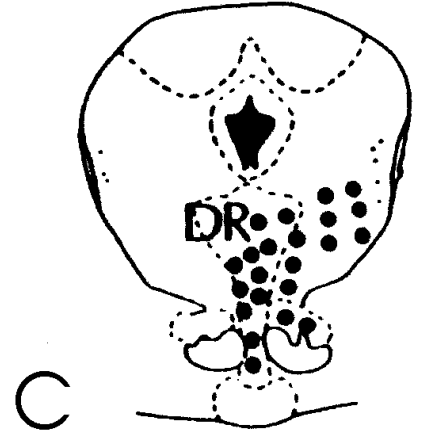

para o núcleo mediano da rafe (Marcinkiewicz et al., 1989)

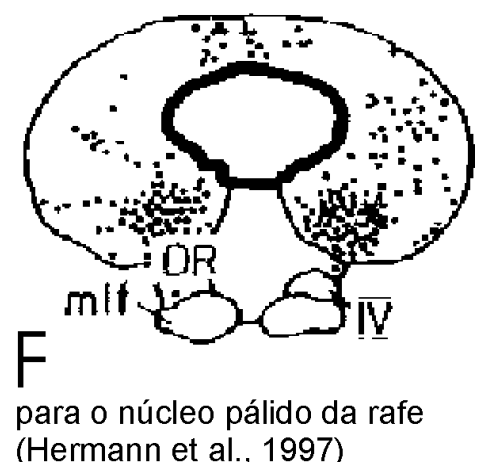

(Hermann et al., 1997)

Fig. 15. Neurônios da MCP que projetam para outras estruturas do SNC. Abreviaturas: III - núcleo do nervo oculomotor; IV - núcleo do nervo troclear; DR - núcleo dorsal da rafe; EW - núcleo de Edinger-Westphal; MCP - matéria cinzenta periaquedutal; mlf - fascílulo longitudinal medial; ND - núdleo de Darkschewitsch; SNC sistema nervoso central.

déficit de condicionamento provocado por sua lesão pode ser compensado com supertreinamento (Maren, 1999). Portanto, esta estrutura deve ser compreendida como uma interface perceptual do sistema límbico, e não como um efetor.

Tálamo

Não há consenso sobre a existência de domínios talâmicos topograficamente organizados para as diversas subdivisões da MCP. Krout \& Loewy (2000) observaram que as terminações da MCP no tálamo originam-se predominantemente da MCPI e MCPvl, inervando os núcleos mediais e intralaminares. Kolmac \& Mitrofanis (1998), num estudo semelhante, 
também não observaram diferenças topográficas claras. Entretanto, Chen \& Su (1990) relataram que os núcleos paraventricular e paratenial do tálamo são inervados por neurônios localizados predominantemente na MCP dorsal, e Risold et al. (1997, Fig.15A) observaram que o núcleo reuniens é inervado preferencialmente pela MCPdl.

\section{Córtex}

No rato, as árias motoras primárias dos membros dianteiros (Fig.13F), traseiros e do tronco (Fig.13G) projetam exclusivamente para a MCPI e MCPvl, enquanto que os córtices auditivo primário (Fig.13B) e visual secundário (Fig.13C) inervam preferencialmente a MCPdl (Newman et al., 1989). Os córtices perirrinal, cingulado anterior (Floyd et al., 2000; Fig.13D) e retrosplenial agranular lateral (Risold et al., 1997; Fig.13E) projetam quase exclusivamente para a MCPdl. Já os córtices orbitais medial, ventrolateral, ventral e dorsolateral, bem como os córtices insulares agranulares dorsal e posterior, projetam para a MCPvl (Floyd et al., 2000). Os córtices pré-límbico e infralímbico são as fronteiras desses domínios topográficos, com suas porções rostroventrais projetando para a MCPvl (Fig.13H), enquanto que suas porções dorsocaudais projetam para a MCPdl. Portanto, as projeções corticais para a MCP são topograficamente distribuídas.

Projeções diretas da MCP para o córtex não são conhecidas. Entretanto, a fuga causada pela estimulação da MCPdl com óxido nítrico leva à ativação do cingulado anterior (de Oliveira et al., 2000). Isto sugere a existência de uma via ascendente ligando funcionalmente ambas regiões. É possível que isto se dê através do tálamo. 
Núcleos rostrais da rafe

O núcleo mediano da rafe $(\mathrm{MnR})$ tem conexões recíprocas diretas com a MCPvl (Marcinkiewicz et al., 1989; Fig.15C) e recebe projeções diretas do PMd. Recentemente, o MnR foi relacionado à retenção do condicionamento ao contexto (Avanzi \& Brandão, 2001).

As projeções do núcleo dorsal da rafe (DR) terminam densamente na MCPvl, mas também na MCPdl ao nível do núcleo oculomotor (Vertes, 1991; Fig13I). As projeções serotonérgicas do DR para a MCP são inibitórias, e provavelmente modulam a atividade de neurônios relacionados ao comportamento defensivo (Lovick, 1994). A MCPvl é a única subdivisão da MCP que envia projeções diretas para o DR (Kalén et al., 1985).

\section{b) Conexões com estruturas caudais}

O fluxo de impulsos nervosos da MCP para os motoneurônios do corno ventral da medula espinhal passa por relés ao nível do núcleo cuneiforme $(\mathrm{CnF})$ e dos núcleos caudais da rafe.

A maioria das projeções da MCP para o CnF partem da MCPdl (Redgrave et al., 1988; Fig.15B). A estimulação química do CnF causa congelamento e fuga, e sua lesão bloqueia as reações de defesa produzidas pela estimulação do colículo superior (Dean et al., 1988), uma região que compartilha esta via com a MCPdl. Neurônios neste núcleo são ativados pela exposição ao odor do predador (Dielenberg et al., 2001) e pela estimulação elétrica da MCP dorsal (Sandner et al., 1992) ou do hipotálamo medial (Sandner et al., 1993). 
Os núcleos caudais da rafe recebem aferentes preferencialmente da MCPdm, MCPI e MCPvl, mas não da MCPdl (Hermann et al., 1997). A MCPvl caudal contém o maior grupo de células que enviam projeções para os núcleos caudais da rafe (Hermann et al., 1997; Fig.15F). Esses núcleos também recebem aferentes do CnF, mas a topografia desta projeção não foi ainda analisada (Cowie \& Holstege (1992). A estimulação química de neurônios na região dos núcleos caudais da rafe causa imobilidade (Morgan \& Whitney, 2000), e sua estimulação elétrica causa fuga (Prado \& Roberts, 1985).

A MCPvl é a única subdivisão que envia projeções diretas para o corno ventral da medula espinhal (Mouton \& Holstege, 1994; Fig.15E). Entretanto, as outras subdivisões podem alcançar motoneurônios somáticos através dos núcleos pálido e obscuro da rafe (Holstege \& Kuypers, 1987).

\section{Funções das subdivisões da MCP}

Assim como na sua organização anatômica, a MCP apresenta muitas especializações regionais quanto às funções que desempenha. A seguir, fazemos uma breve revisão de funções relacionadas à defesa desigualmente representadas entre suas subdivisões.

Sensoriais - dor e analgesia

A MCP é alvo de aferências nociceptivas provenientes da chamada via espinomesencefálica da dor (Yezierski, 1988; Willis \& Westlund, 1997). Melzack et al. (1958) mostraram que a lesão da MCP atenua significativamente a percepção da dor em gatos. 
Blomqvist \& Craig (1991) demonstraram que as aferências medulares à MCP têm origem principalmente na lâmina I do corno dorsal e fazem sinapse nas regiões lateral e ventrolateral caudal da MCP, contralateralmente. Essa origem possivelmente indica que essas fibras transportam informação nociceptiva, termorreceptiva e viceroceptiva. A estimulação da MCP em humanos pode provocar sensações de dor e queimação (Nashold et al., 1969).

Ao estudar as projeções do alargamento cervical para a MCP, Keay e Bandler (1992) relataram que a MCPI é alvo preferencial da lâmina I e do núcleo lateral cervical, enquanto que a MCPvl recebe mais informação das lâminas VII, VIII e X. Essas estruturas, por sua vez, recebem respectivamente informação cutânea e muscular. Estimulação dolorosa cutânea causa expressão da proteína Fos em toda a MCP com predominância na MCPI, enquanto que a estimulação dolorosa muscular causa um aumento mais acentuado na MCPvl (Keay \& Bandler, 1993). Estimulação dolorosa articular, cardiopulmonar e peritonial também resultam em ativação semelhante na MCPvl (Clement et al., 1996).

No entanto, a interpretação de que a MCPI estaria relacionada à dor cutânea e a MCPvl à dor profunda foi revista recentemente (Keay et al., 2001). Ao submeter animais a dor cutânea persistente inescapável, o padrão de ativação da MCP foi semelhante ao da dor profunda, com ativação predominante na MCPvl. Dor cutânea intermintente, por outro lado, ativa preferencialmente a MCPI (Keay \& Bandler, 2002, Fig.16). Isto sugere que a ativação da MCP não está relacionada à origem da dor, como se supunha, mas sim com a resposta somática mais adequada àquela (Keay \& Bandler, 2002), como veremos mais adiante.

A estimulação da MCP também é capaz de provocar analgesia. Reynolds (1969) conseguiu analgesia tão profunda com a estimulação da formação reticular próxima à MCP, 
que pôde executar laparotomia exploratória, sem a utilização de anestesia química, em ratos conscientes. Analgesia provocada por estimulação também foi relatada em seres humanos (Hosobuchi et al., 1977). Vários estudos se seguiram mostrando que a analgesia poderia ser provocada a partir de quase todas as subdivisões da MCP. Entretanto, como Besson et al. (1991) apontam, a maioria desses estudos pareceu ignorar outras alterações comportamentais que acompanham a estimulação da MCP, notadamente respostas defensivas. No trabalho destes autores, apenas uma pequena região da MCPvl pode ser considerada como analgésica "pura", enquanto todas as outras regiões provavelmente têm analgesia secundária à aversão. Essa crítica foi rebatida por Morgan et al. (1987), que observaram que doses de diazepam microinjetadas na região estimulada eram capazes de bloquear a resposta defensiva, sem, no entanto, modificar o limiar de dor, sugerindo que
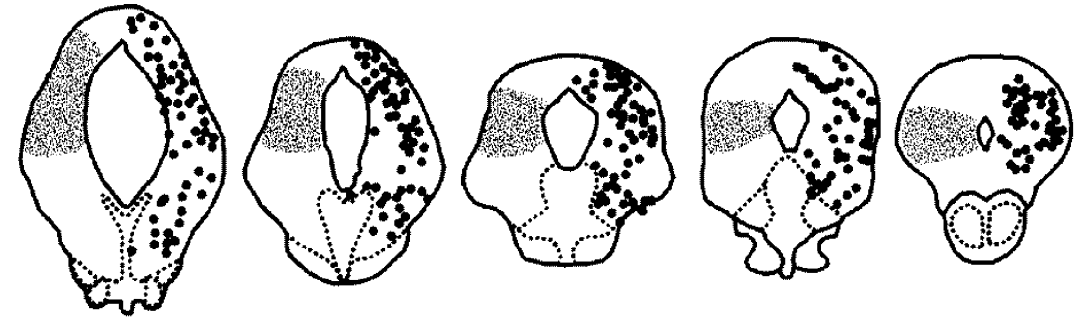

Dor cutânea intermitente (calor aplicado ao pescoço)
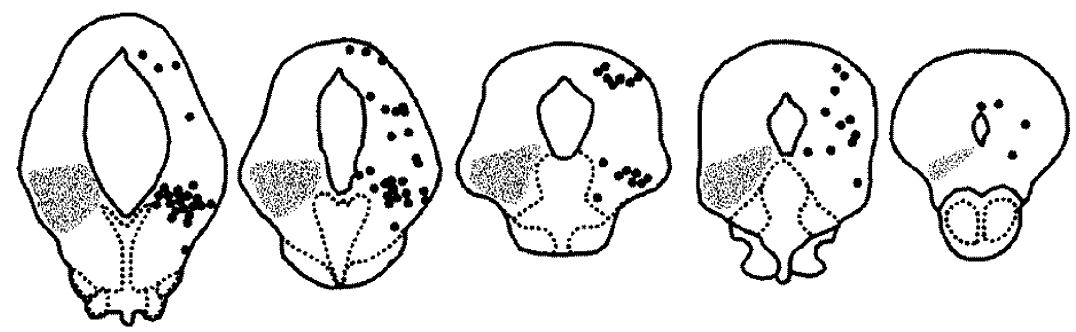

Dor cutânea persistente (clip preso ao pescoço)

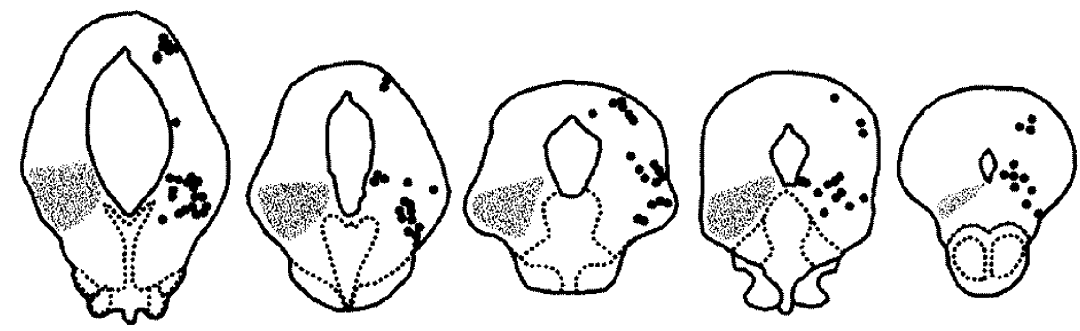

Dor somática profunda (formalina em músculo do pescoço)
Fig. 16. Imunorreatividade Fos em neurônios da MCP provocada por dor escapável (dor cutânea intermitente) ou escapável (dor cutânea persistente e dor somática profunda (Keay \& Bandler, 2002). Os pontos representam neurônios imunorreativos à proteína Fos. A área marcada em cinza assinala a subdivisão da MCP onde a expressão de Fos foi mais intensa. 
os substratos neuroniais da aversão e da analgesia na MCP podem ser dissociados. Entretanto, a evidência mais clara para uma diferenciação regional desta função na MCP é que a analgesia provocada por estimulação pode ser revertida com naloxona na maioria dos sítios da MCPvl, enquanto que na MCPI, MCPdl e MCPdm o mesmo não ocorre (Thorn et al., 1989), sugerindo uma mediação opióide apenas na MCPvl. Coerentemente, a analgesia provocada pela eletroacupuntura ativa preferencialmente células da MCPvl, mas sob algumas circunstâncias ativa também as outras subregiões (Lee \& Beitz, 1993).

Viscerais - controle cardiovascular e micção

A partir de estudos com gatos descerebrados, Carrive et al. (1989) foram os primeiros a descrever funções diferentes entre regiões da MCP com base em variáveis cardiovasculares. Na MCP caudal, a estimulação química provocou forte vasodilatação da artéria ilíaca externa. Este padrão contrariava o que havia sido descrito anteriormente para a MCP rostral, onde se havia verificado exatamente o oposto (Carrive et al., 1987). Posteriormente, verificou-se que os sítios que provocam vasoconstrição ilíaca (MCP rostral) também promovem vasodilatação na artéria carótida concomitantemente, enquanto que na MCP caudal o oposto é observado (Bandler et al., 1991). Essas diferenças, como veremos adiante, são coerentes com as demandas de diferentes respostas somáticas mediadas pela MCP.

Mas as descobertas mais surpreendentes foram as relacionadas com a oposição entre as funções da MCPI e da MCPvl. Enquanto a estimulação da MCPI causou aumentos na pressão sangüínea, na MCPvl o oposto foi observado (Zhang et al., 1990). A hipertensão 
Hipertensão
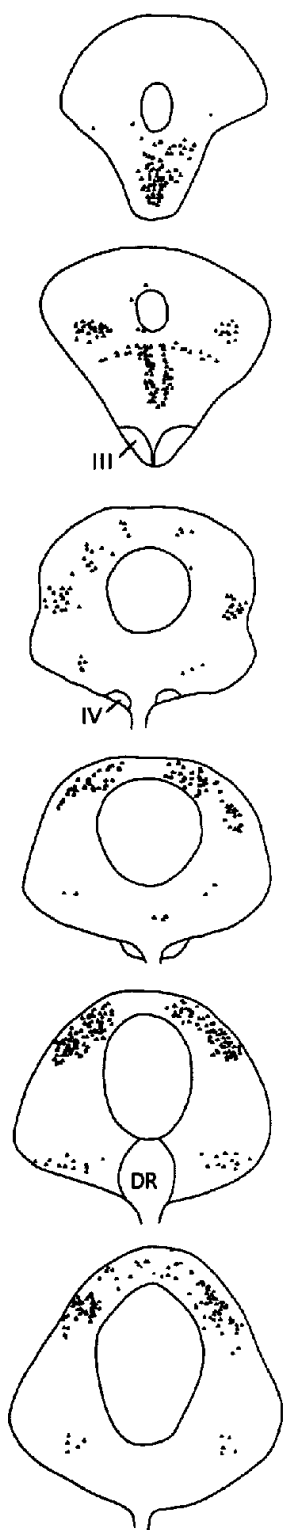
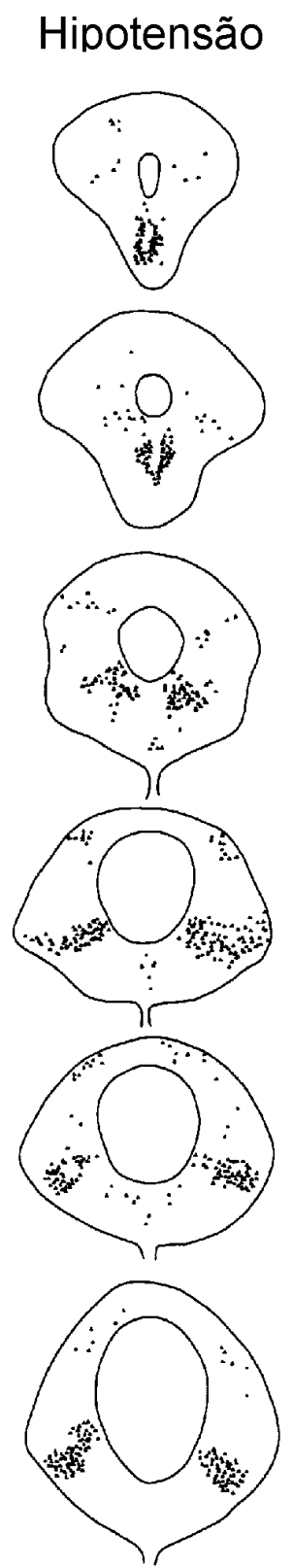

Veículo
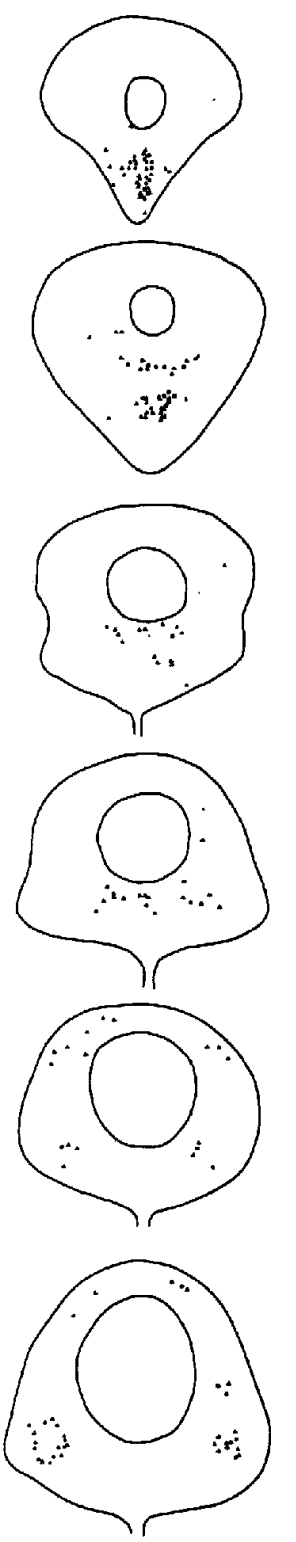

Fig. 17. Imunorreatividade Fos em neurônios da MCP provocada pela infusão de vasoconstritor (fenilefrina), vasodilatador (nitroprussida), ou veículo (salina; Murphy et al., 1995). Os pontos representam neurônios imunorreativos à proteína Fos.

induzida farmacologicamente causa expressão Fos na MCPI e MCPdl, enquanto que a hipotensão ativa a MCPvl (Murphy et al., 1995, Fig.17). Mais interessante ainda, esse controle da pressão é distribuído desigualmente no eixo rostrocaudal, com a porção mais rostral de ambas subdivisões alterando o tônus arterial dos membros posteriores e a porção caudal controlando o tônus arterial visceral (Bandler et al., 1991; Carrive, 1991).

A MCP também está também envolvida com o controle da micção. A maioria dos sítios onde a estimulação provoca a contração da bexiga fica na MCPvl (Taniguchi et al., 2002). 
Somáticas - comportamento defensivo

O controle da MCP sobre os comportamentos de defesa também não está distribuído de forma homogênea, mas também sugere especializações regionais. LeDoux et al. (1988) observaram uma redução do congelamento condicionado após a lesão neuroquímica da MCP caudal, mas não da MCP rostral. Carrive et al. (1989) também observaram uma diferenciação rostrocaudal ao estimular a MCP de gatos descerebrados com aminoácidos excitatórios. Enquanto a estimulação da porção rostral da MCP causa uma expressão de ameaça defensiva, nos sítios mais caudais foram provocados movimentos vigorosos das patas traseiras. Neste contexto, as mudanças concomitantes na irrigação sangüínea da face (artéria carótida) e das patas traseiras (artéria ilíaca), descritas anteriormente, se encaixam como parte das respostas viscerais necessárias para a execução de cada uma destas respostas defensivas.

Inspirado por estudos sobre a mediação química da analgesia na MCP, que já indicavam uma diferenciação da MCP no eixo dorsoventral, Fanselow (1991) investigou o efeito da lesão ou estimulação elétrica nesta estrutura. A estimulação elétrica da região dorsal e lateral da MCP do rato provoca reações motoras vigorosas, semelhantes às provocadas por choque nas patas, e logo após o término desta o animal passa a congelar. Já durante a estimulação da porção ventral, apenas congelamento foi observado. A lesão da MCP ventral, por sua vez, diminuiu o congelamento condicionado, e a lesão da MCP dorsal, a "explosão de atividade" que acontece durante a apresentação do choque nas patas. De forma semelhante, Monassi et al. (1997) relataram uma diminuição na duração de episódios de imobilidade tônica na cobaia durante a estimulação da MCPdl com carbacol, e na MCPvl 


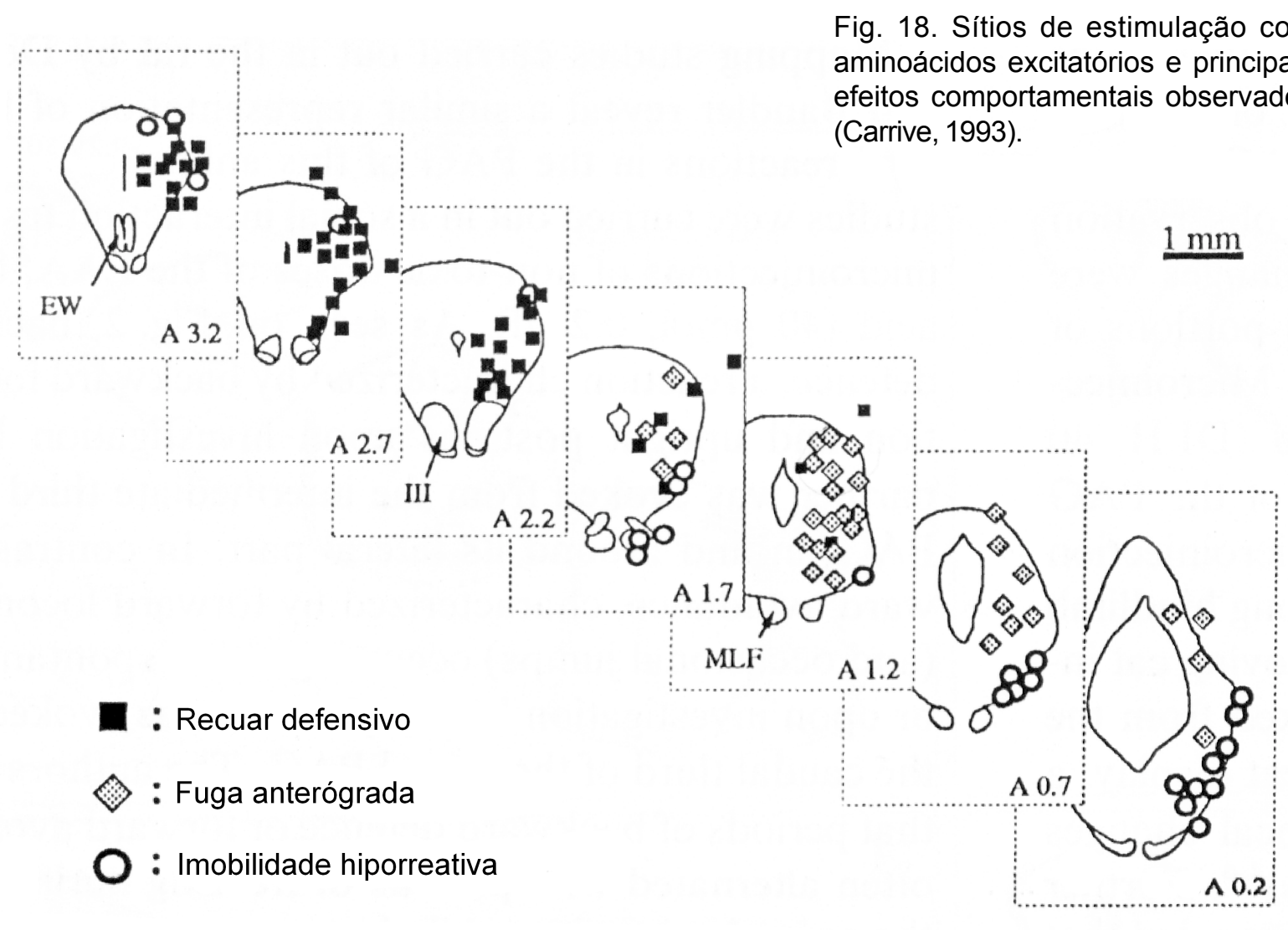

um aumento. Ou seja, estes resultados foram consistentes com a hipótese de que a MCP dorsal mediaria respostas ativas como a fuga, enquanto que a MCP ventral estaria mais relacionada às respostas imóveis.

Também no eixo dorsoventral, Bandler et al. (1991) observaram uma diferenciação funcional. A estimulação da MCPI do gato causa fuga vigorosa, enquanto que a da MCPvl causa forte imobilidade. Tanto estes quanto os achados de Carrive et al. (1989) foram posteriormente reproduzidos no rato (Carrive, 1993, Fig.18). Segundo Depaulis et al. (1994), esta imobilidade faria parte de uma resposta de recuperação após encontro com um predador ou agressor conspecífico, chamada por estes de quiescência. A necessidade de ficar quieto nesta situação lembra que isto também é válido no caso da dor inescapável, também relacionada com a ativação da MCPvl (Keay \& Bandler, 2002). Estes autores sugerem que naquele caso, esta atividade não estaria relacionada com a percepção da dor, 
mas sim com a resposta que seria emitida em face àquela.

Mas estes achados trouxeram consigo algumas inconsistências. A imobilidade observada após a microinjeção de glutamato na MCPvl (Depaulis et al., 1994) é muito diferente da resposta de congelamento que é atenuada após a lesão da mesma subregião (Fanselow, 1991). Enquanto que a primeira é acompanhada de hipotensão, bradicardia e hiporreatividade (Depaulis et al., 1994), o congelamento é acompanhado de hipertensão (Carrive, 2000) e hipervigilância (Blanchard \& Blanchard, 1988).

Recentemente, Morgan e Carrive (2001) contestaram a pretensa relação entre a imobilidade provocada pela estimulação da MCPvl e a hipotensão, bem como a sugestão feita por Depaulis et al. (1994) de que esta imobilidade estaria relacionada apenas com a quiescência. Após a microinjeção de ácido $D, L$ homocistéico na $M C P v l$ de ratos não sedados e não restritos, a imobilidade e bradicardia que se seguiram não foram acompanhadas por queda na pressão sangüínea, como observado em ratos sedados. Os autores concluem que, embora diferentes comportamentos sejam mediados por diferentes conjuntos de estruturas encefálicas, estes conjuntos podem conter interseções, e que a MCPvl potencialmente mediaria tanto o congelamento quanto a quiescência.

Esta hipótese de coativação recebe suporte de vários estudos correlacionais. A imunorreatividade à enzima c-Fos, relacionada à ativação de neurônios, é aumentada após a estimulação da MCP dorsal (Sandner et al., 1992) e do hipotálamo medial (Sandner et al., 1993), após a exposição a um predador (Canteras \& Goto, 1999, Fig.19 esquerda) ou ao seu cheiro (Dielenberg et al., 2001) e durante a re-exposição a um contexto aversivamente condicionado (Carrive et al., 1997, Fig 19 direita) em todas as subdivisões da MCP. Entretanto, há um predomínio da ativação da MCPdl durante a exposição ao predador e da MCPvl 

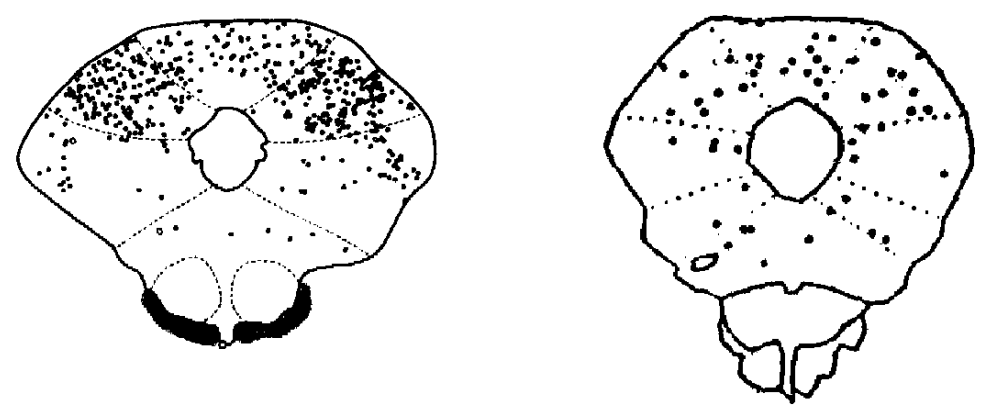

Fig. 19. Imunorreatividade Fos em neurônios da MCP provocada pela exposição ao predador (esquerda; Canteras \& Goto, 1999) ou a um contexto previamente associado ao choque nas patas (direita; Carrive et al., 1997).
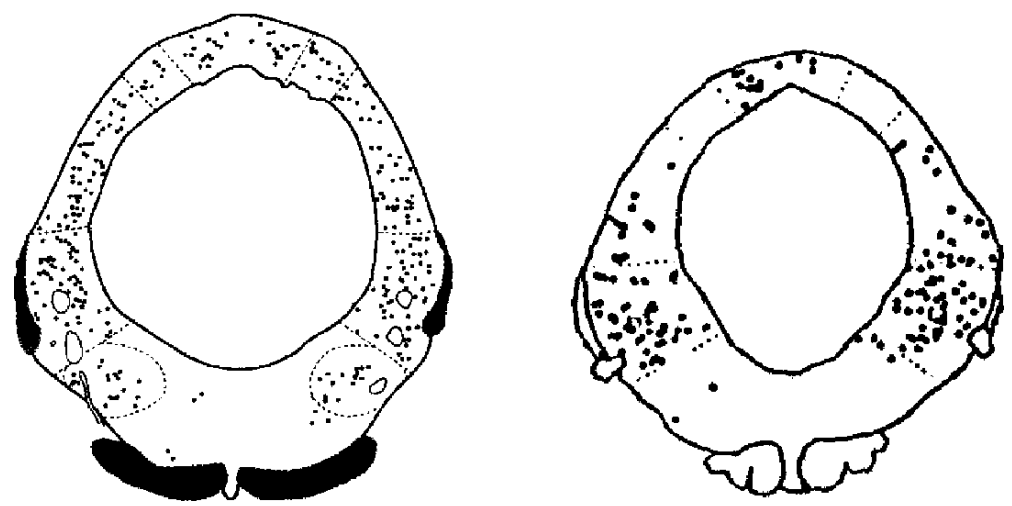

durante a exposição ao contexto aversivamente condicionado. Isto é coerente com a teoria de Fanselow (1991), pois a exposição ao predador provocou fuga (Canteras e Goto, 1999) e a exposição ao contexto, congelamento (Carrive et al., 1997). Entretanto, o cheiro do predador causa predominantemente congelamento (Wallace \& Rosen, 2000) e ativação da MCPdl e MCPdm (Dielenberg et al., 2001), o que contraria a teoria de Fanselow (1991).

Mais, o congelamento ocorre durante a estimulação elétrica (Brandão et al., 1982; Coimbra \& Brandão, 1993; Schenberg et al., 1990) e química (Krieger \& Graeff, 1985; Bandler et al., 1985) dos mesmos sítios que provocam fuga, e freqüentemente em antecipação a esta. Esta forma de congelamento é acompanhada de tensão muscular, hipervigilância, e hiperreatividade (Bandler et al., 1985), reminiscentes do congelamento condicionado. Ou seja, estes trabalhos não forneceram evidências em favor da hipótese da separação anatômica entre os substratos do congelamento e da fuga.

Fanselow (1991) sugeriu que o congelamento observado após a estimulação da MCP dorsal seria semelhante ao que ocorre após a exposição ao choque nas patas. Daí 
depreende-se que a estimulação da MCP dorsal, que é aversiva (Schmitt et al., 1974) e pode causar condicionamento (Di Scala et al., 1987), poderia ser responsável por este congelamento através de condicionamento contextual. Ou seja, a estimulação dos sítios da MCP que provocam fuga funcionaria como estímulo incondicionado, e se associaria às pistas contextuais presentes na sessão experimental. Estas, uma vez associadas à estimulação, passariam a provocar a resposta condicionada de medo no rato, ou seja, o congelamento. Entretanto, o congelamento provocado pela estimulação da MCPdl persiste mesmo após retirarmos o animal do ambiente onde a sessão experimental ocorreu, e não permanece após 24 h (Vianna et al., 2001c).

Outra explicação coerente com a hipótese da separação anatômica entre congelamento e fuga seria a propagação do estímulo da MCP dorsal para a MCPvl. Esta hipótese também não recebeu suporte empírico. Após o término da estimulação da MCPvl em intensidade suficiente para provocar fuga, os animais não congelaram mais do que controles que não foram estimulados, como acontece após a estimulação da MCPdl (Vianna et al., 2001a). Entretanto, mesmo neste caso a MCPvl poderia participar da resposta, não porque ativada pela propagação pura e simples da corrente elétrica através do tecido, mas por fazer parte de um circuito neuronial maior, cuja ativação poderia ser provocada pela estimulação da MCPdl, mas não da MCPvl. Ou seja, baseando-se neste raciocínio, não seria possível afirmar com certeza se o congelamento provocado pela estimulação da MCPdl depende ou não da ativação da MCPvl. 


\section{Objetivos}

Os resultados publicados até agora permitem duas interpretações igualmente plausíveis para o papel das diferentes subdivisões da MCP na mediação da resposta de congelamento:

a) O congelamento, assim como a quiescência e a imobilidade tônica, são mediados pela MCPvl. O congelamento visto durante a estimulação da MCPdl é resultado da ativação trans-sináptica da MCPvl.

b) $\quad \mathrm{O}$ congelamento mediado pela MCPdl, embora semelhante ao congelamento condicionado, é independente da ativação da MCPvl.

Este trabalho procurou solucionar este impasse. Por meio de lesões abrangentes da MCPvl, pudemos avaliar até que ponto o congelamento provocado pela estimulação da MCPdl depende da MCPvl. 
Métodos 
Sujeitos- Ratos albinos Wistar, machos, experimentalmente ingênuos, pesando de 250 a $300 \mathrm{~g}$. Antes de serem usados nos experimentos, os animais foram mantidos em gaiolasviveiro com no máximo 7 animais, e providos de água e comida ad libitum. A temperatura ambiente do biotério foi mantida em $22 \pm 1^{\circ} \mathrm{C}$, sob um ciclo claro/escuro de 12/12 (luzes acesas às 7:00 h). Todos os treinos e testes ocorreram durante o período iluminado do ciclo.

Cirurgia- Os animais foram anestesiados com tribromoetanol (250 mg/kg), e colocados em um estereotáxico. Após a anestesia procedeu-se à assepsia local com álcool iodado, seguido de anestesia subcutânea local (lidocaína a 2\%). O calvário foi exposto e o periósteo removido com o auxílio de pinça e tesoura. Aquecimento por um secador de cabelo comum facilitou a visualização de lambda.

Cada animal foi alocado a um de dois grupos. Em um destes, lesões eletrolíticas foram feitas bilateralmente na MCPvl (coordenadas estereotáxicas partindo de lambda: 0,8 $\mathrm{mm}$ posterior, $1,0 \mathrm{~mm}$ lateral e $6,0 \mathrm{~mm}$ ventral) com um eletrodo monopolar de aço inox (agulha de acupuntura isolada exceto no corte transversal da ponta). As lesões foram feitas passando corrente contínua (2 mA) anodal (ESF-108, Del Vecchio, Brazil) por $60 \mathrm{~s}$ pelo eletrodo. No outro grupo (falso-operado) os animais foram submetidos a procedimentos cirúrgicos idênticos aos acima descritos, excetuando-se a passagem de corrente pelo eletrodo da lesão.

Nos animais do experimento 1 ( $\mathrm{N}=8$ para ambos os grupos), após a lesão da MCPvl, os animais foram implantados com um eletrodo bipolar unilateral (Plastics One) direcionado à MCPdl. O eletrodo era feito de aço inox, $160 \mu \mathrm{m}$ de diâmetro, isolado exceto no corte 
transversal da ponta, e foi introduzido na MCPdl em ângulo de $16^{\circ}$ nas coordenadas $1,9 \mathrm{~mm}$ lateral e 5,1 mm ventral a lambda. O eletrodo da MCPdl foi fixado ao crânio por meio de resina acrílica e três parafusos de aço inox. Nos animais do experimento 2 ( $N=9$ para ambos os grupos), em lugar do eletrodo, foi implandada na MCPdl uma cânula-guia unilateral de aço inox (13 mm de comprimento e 0,6 de diâmetro externo) em ângulo de $16^{\circ}$ nas coordenadas 1,9 mm lateral e 4,2 $\mathrm{mm}$ ventral a lambda.

Histologia- Ao final de cada experimento, todos os animais foram sacrificados através de uma grande dose de uretana. Após serem perfundidos cardiacamente com salina e formol (10\%), seus encéfalos foram extraídos e guardados numa solução de formol (10\%) por pelo menos uma semana. Cortes seriais de $50 \mu \mathrm{m}$ de espessura foram obtidos por meio de um criostato. Os cortes foram então montados em lâminas de microscopia e corados com vermelho neutro para a verificação das lesões. Representações da região cerebral afetada pela lesão foram feitos em diagramas correspondentes do atlas de Paxinos \& Watson (1997).

Equipamento- Para a observação dos efeitos comportamentais da estimulação da MCPdl, os animais foram colocados em uma arena circular (60 cm de diâmetro e $50 \mathrm{~cm}$ de altura) com a sala iluminada por uma lâmpada fluorescente de 40 W (360 lux no nível do assoalho da arena).

Experimento 1- O assoalho da arena foi demarcado em 12 seções, de forma que a atividade locomotora dos animais pudesse ser quantificada nos 6 min iniciais de cada sessão experimental. A estimulação elétrica da MCPdl foi feita através de um estimulador de 
onda senoidal (Del Vecchio, Ribeirão Preto), ligado a um osciloscópio, que indicou a queda de voltagem através de um resistor de $100 \mathrm{KW}$ colocado em série com o rato. Sobre a arena foi colocado um conector elétrico giratório (Plastics One), ligado à saída do estimulador. Um fio elétrico ligava o conector ao eletrodo situado na cabeça do animal, de forma que seus movimentos não foram prejudicados.

Os testes de condicionamento aversivo foram realizados em uma caixa experimental medindo $25 \times 20 \times 20 \mathrm{~cm}$. Três paredes laterais da caixa experimental eram de alumínio e as restantes de acrílico transparente. O assoalho da caixa experimental era composto por barras de aço inox de $5 \mathrm{~mm}$ de diâmetro distando $1,5 \mathrm{~cm}$ entre si. A caixa foi limpa imediatamente antes da introdução de cada animal com uma solução de hidróxido de amônio (5\%). A caixa experimental estava encerrada dentro de uma câmara de isolamento acústico feita de compensado de madeira e revestimento acústico. Uma lâmpada de $8 \mathrm{~W}$ instalada na câmara de isolamento acústico permitiu a observação do animal através de uma janela de vidro de $15 \times 20 \mathrm{~cm}$. Uma ventoinha instalada na câmara de isolamento acústico permitiu a apresentação contínua de um ruído de fundo de $78 \mathrm{~dB}$ (escala A). Choques elétricos foram originados de um gerador de corrente alternada com misturador de voltagem (Del Vecchio, Ribeirão Preto). Este aparelho foi ajustado para fornecer choques de $1.0 \mathrm{~mA}$ às grades do assoalho da caixa experimental.

Experimento 2- O comportamento dos animais foi observado na mesma arena do experimento 1, dessa vez com o assoalho coberto por papel pardo para facilitar a filmagem das sessões experimentais. A microinjeção foi feita através de uma seringa Hamilton de 5 $\mu$ conectada a um tubo de polietileno e a uma agulha dental $(0,3 \mathrm{~mm}$ de diâmetro externo) 
que ultrapassava o comprimento da cânula-guia em $1 \mathrm{~mm}$. Com o animal envolvido em um pano, esta agulha era inserida na cânula-guia, e removida após 20 s do término da infusão. Um volume de $0,2 \mu$ foi injetado durante 20 s com a ajuda de uma bomba de infusão (Harvard Apparatus). Uma bolha de ar dentro do tubo de polietileno conectando a seringa à agulha intracerebral foi usada para monitorar a injeção. Cada rato recebeu apenas uma injeção de semicarbazida (Sigma, $8 \mu \mathrm{g} / 2 \mu \mathrm{l})$.

Procedimento- Todos os animais foram submetidos ao mesmo procedimento. Logo após a cirurgia, foram transferidos para gaiolas-viveiro em duplas, e providos de água e comida ad libitum.

Experimento 1- No sexto dia após a cirurgia, cada animal foi colocado na arena e seu comportamento ambulatório foi avaliado por $6 \mathrm{~min}$, por meio da contagem do número de seções do assoalho onde o animal entrou com ambas patas traseiras. Após isto, foi realizada a medição dos limiares de congelamento e fuga. Estimulação elétrica $(C A, 60 \mathrm{~Hz}$, 15s) foi apresentada em intervalos de $1 \mathrm{~min}$ com a intensidade da corrente aumentando de 5 em $5 \mu \mathrm{A}$ após cada intervalo. O limiar de congelamento foi definido operacionalmente como a menor intensidade produzindo imobilidade exceto a necessária para respiração, com presença de exoftalmia, por 6 segundos. A intensidade de corrente que produzisse corrida (galope) ou saltos foi considerada o limiar de fuga. Animais com um limiar de fuga acima de $70 \mu \mathrm{A}$ (pico a pico) foram descartados do experimento. Após a determinação dos limiares aversivos, os animais foram levados de volta às suas gaiolas.

No dia seguinte, os animais foram colocados na caixa experimental, onde permane- 
ceram por $6 \mathrm{~min}$. Após isto, receberam 5 choques (5s, $1.0 \mathrm{~mA}, 60 \mathrm{~s}$ de intervalo entre tentativas), e em seguida foram recolocados em suas gaiolas-viveiro onde ficaram por mais 24 h. No dia após o condicionamento, os animais foram recolocados na caixa experimental e observados por 6 min para avaliação do condicionamento aversivo. Nenhum choque foi apresentado durante este teste. O congelamento foi definido como a ausência total de movimento do corpo e vibrissas, exceto o necessário para a respiração (De Oca et al., 1998). A medida usada para quantificar a aversão foi a percentagem de tempo gasto em congelamento durante o período de teste. O congelamento também foi mensurado durante os 6 min de habituação à caixa experimental, logo antes da administração dos choques. Para o registro, a cada 2 s o comportamento do animal era julgado como congelamento ou atividade.

Experimento 2- No sexto dia após a cirurgia, animais falso-operados e lesados receberam microinjeções de semicarbazida na MCPdl, e foram colocados dentro da arena para 60 min de sessão. O comportamento dos animais foi registrado em videotape para posterior análise. A arena foi limpa após cada sessão com uma solução de álcool a $20 \%$. Cada rato foi testado apenas uma vez. Somente animais que apresentaram fuga foram incluídos na análise dos resultados.

Análise dos resultados- Tempo de congelamento e fuga ou limiares para respostas de congelamento ou fuga são apresentados como média \pm EPM. Dados foram analisados usando o teste t de Student, e no caso do teste de condicionamento do Experimento 1, a análise de variância de duas vias, com choque (pré x pós) como variável intragrupal e lesão (lesados $\mathrm{x}$ falso-operados) como variável intergrupal. No experimento 1 , oito animais foram 
estudados em cada grupo, exceto para a comparação do limiar de congelamento, onde um animal falso-operado e um lesado foram excluídos por não ter apresentado congelamento antes de atingir o limiar de fuga. No experimento 2, congelamento foi definido operacionalmente como imobilidade completa, exceto por movimentos necessários à respiração, com presença de exoftalmia, apresentados entre o primeiro e o último evento de fuga, pelo período mínimo de 6 segundos consecutivos. O comportamento de fuga foi definido como galope ou salto. Nove animais foram estudados em cada grupo (animais falsooperados e lesados).

Um valor de $p$ igual ou inferior a 0,05 foi considerado significativo. 
Resultados 


\section{Histologia.}

A análise histológica indicou que todos os ratos lesados neste estudo tiveram toda a MCPvl no nível do núcleo cuneiforme comprometida. Uma lesão representativa pode ser vista na figura 20, e fotomicrografias representativas da lesão e do sítio de microinjeção em outro animal podem ser vistas na figura 21. As lesões atingiram a MCPvl bilateralmente, e em alguns casos, danificaram o núcleo dorsal da rafe e se estenderam às regiões laterais da MCP. Os eletrodos ou cânulas foram colocados na MCPdm e MCPdl, e em um único caso, na MCPI (Fig. 22).

\section{Experimento 1- Estimulação elétrica da MCPdl x lesão da MCPvl}

Os comportamentos de congelamento e fuga ocorreram nesta ordem, enquanto a intensidade da estimulação elétrica era gradualmente aumentada $(22,85 \pm 6,02 \mu \mathrm{A}$ para congelamento e 54,38 $\pm 5,45 \mu \mathrm{A}$ para fuga). Como é visível na figura 23 , a lesão da $\mathrm{MCPvl}$ não modificou o limiar aversivo da estimulação elétrica da MCPdl para as respostas de congelamento $(t=0,43 ; p>0,05 ; g l=12)$ ou fuga $(t=1,44 ; p>0,05 ; g l=14)$. Em contraste, a análise de variância relativa ao teste de condicionamento ao contexto revelou efeitos principais para as variáveis choque $[F(1,14)=40,22 ; p<0,001]$, lesão $[F(1,14)=11,88 ; p<0,005]$ e para a interação entre estes fatores $[F(1,14)=11,16 ; p=0,005]$. Testes $t$ complementares mostraram que as mesmas lesões atenuaram o congelamento induzido pelo contexto previamente associado ao choque nas patas $(\mathrm{t}=3,44 ; p<0,005 ; \mathrm{gl}=14)$, como sugere $\mathrm{o}$ par de colunas da direita na figura 24. O par da esquerda na mesma figura mostra que a quantidade de congelamento era muito pequena e semelhante em ambos grupos experimentais antes do condicionamento ( $\mathrm{t}=1,75 ; p>0,05 ; \mathrm{gl}=14)$. Digno de nota, a lesão não aboliu com- 

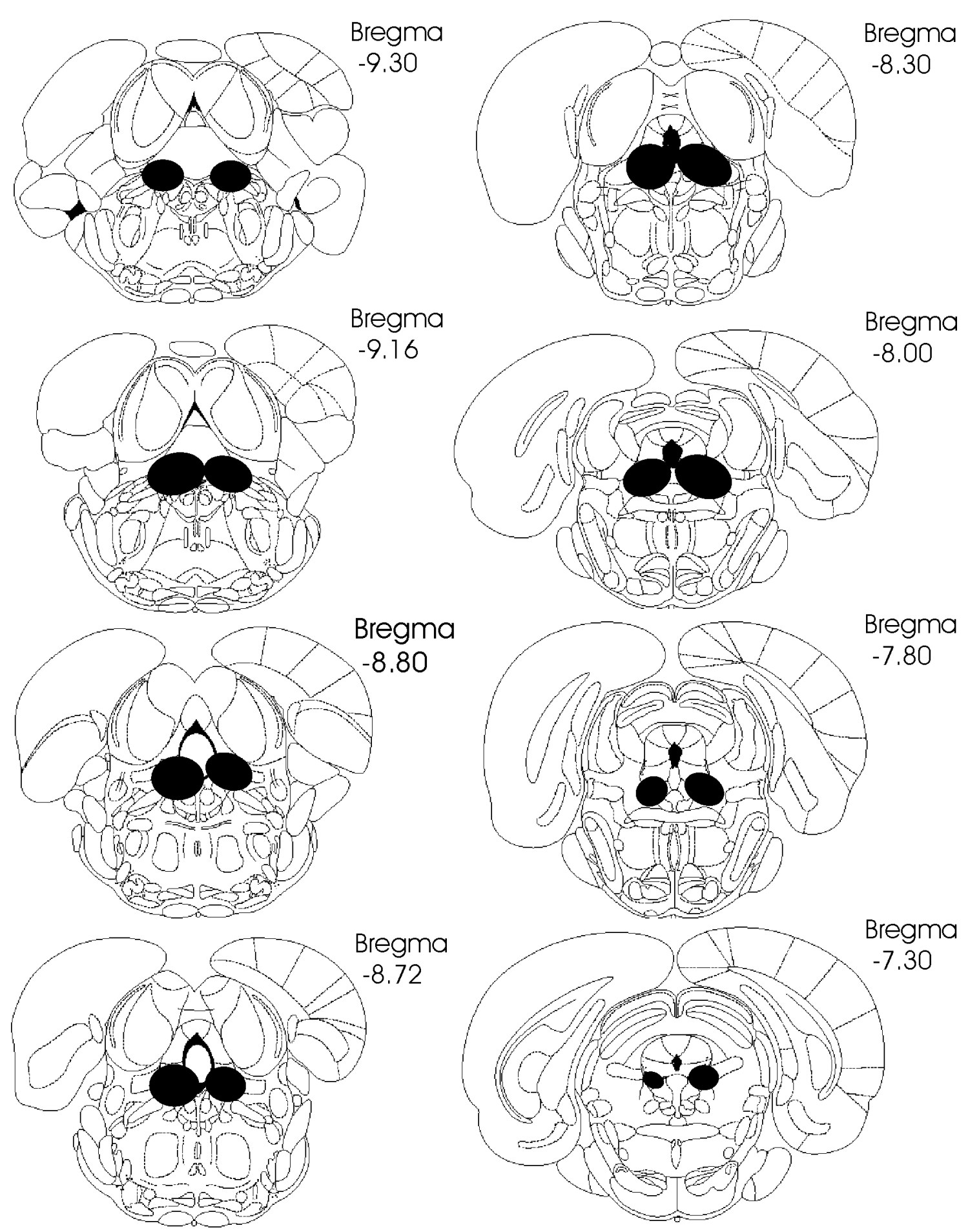

Figura 20: Representação esquemática de lesão na MCPvl. 


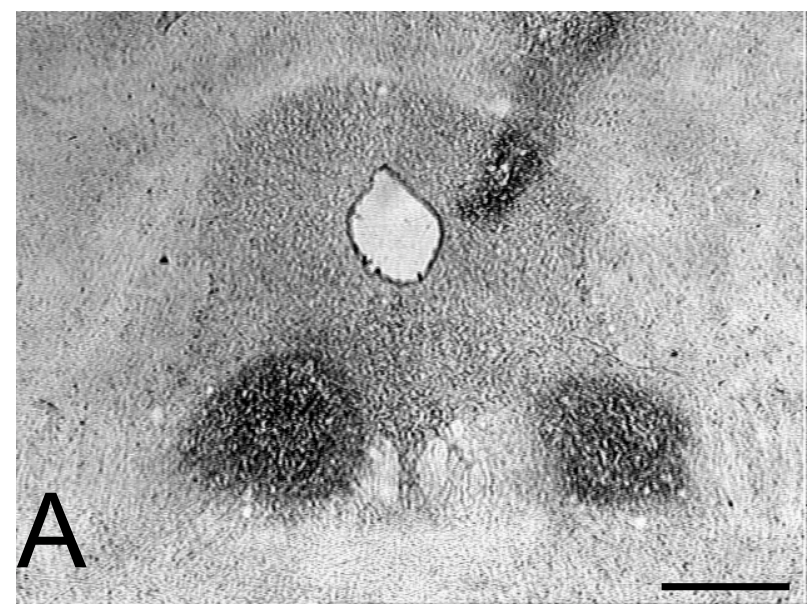

Bregma -7.80

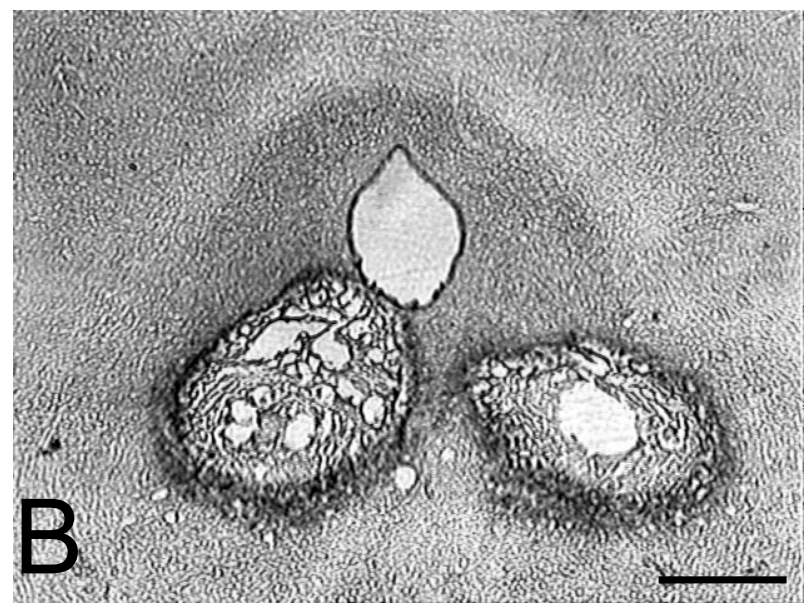

Bregma -8.30

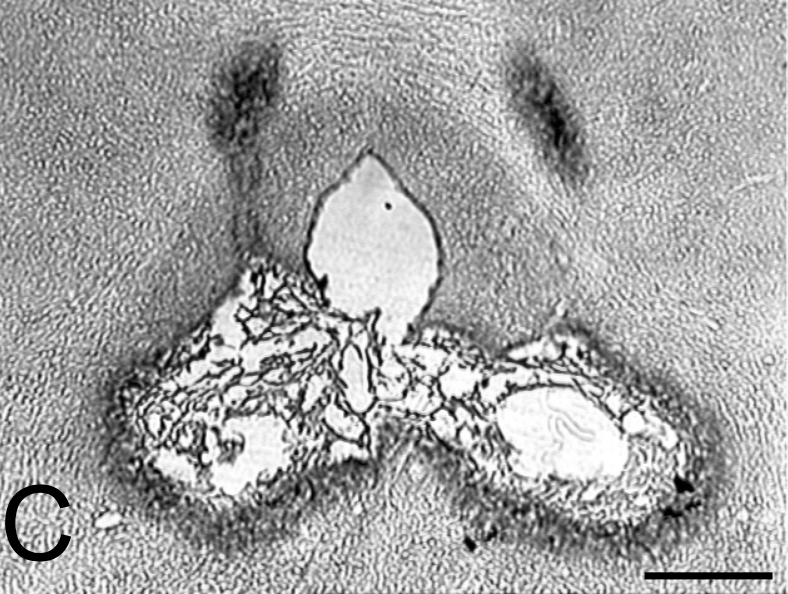

Bregma -8.72

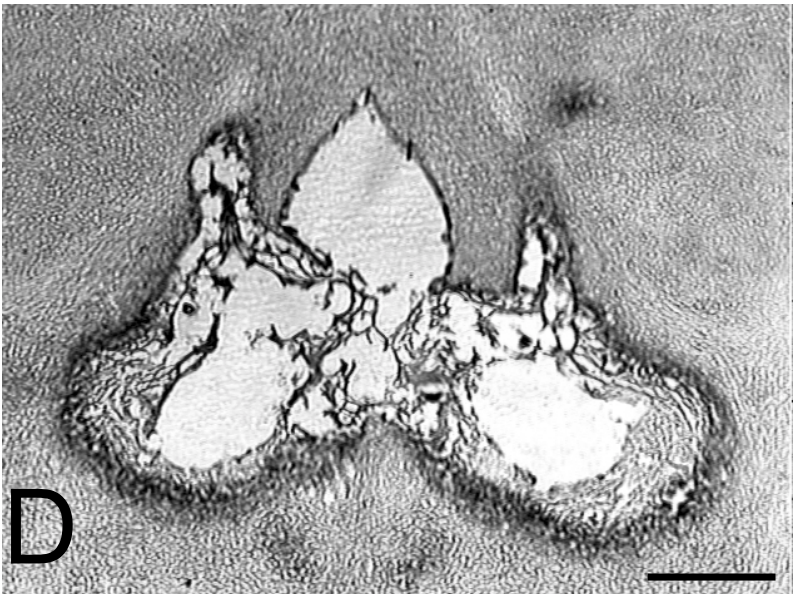

Bregma -8.80

Figura 21: Fotomicrografias de secções transversas da MCP ao nível da MCPvl, representativas da lesão $(A, B, C, D)$ e do sítio de microinjeção $(A)$ em um animal do experimento 2. As barras representam $500 \mu \mathrm{m}$. 


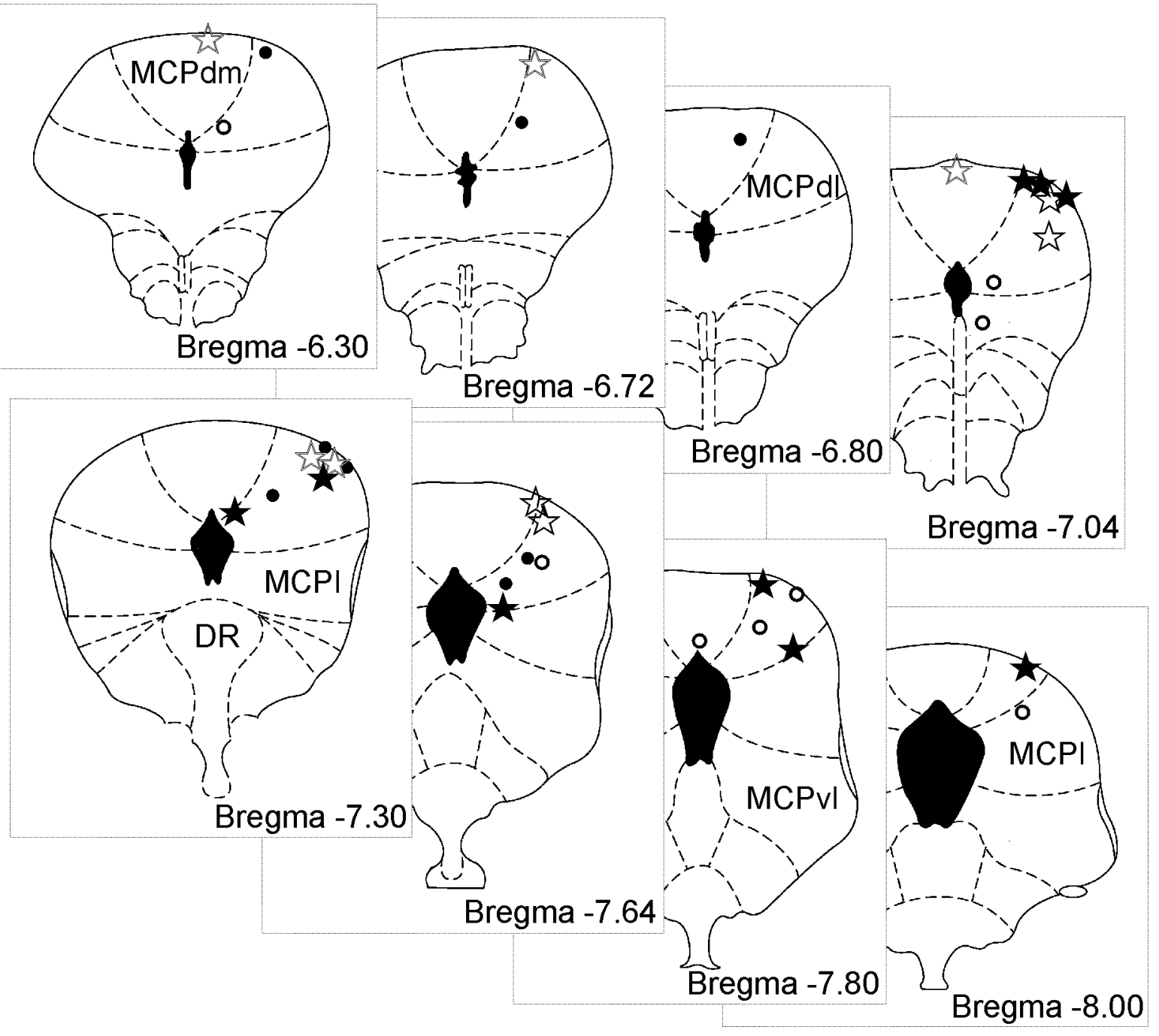

Figura 22: Sítios de estimulação na MCP. Animais falso-operados submetidos à estimulação elétrica $(\bigcirc)$ ou química $(\succsim)$. Animais lesados submetidos à estimulação elétrica $(\mathbf{O})$ ou química $(\star)$. Abreviaturas: DR - núcleo dorsal da rafe; MCP - matéria cinzenta periaquedutal; MCPdl - MCP dorsolateral; MCPdm - MCP dorsomedial; MCPI - MCP lateral; MCPvl - MCP ventrolateral. 


\section{Limiares Aversivos}

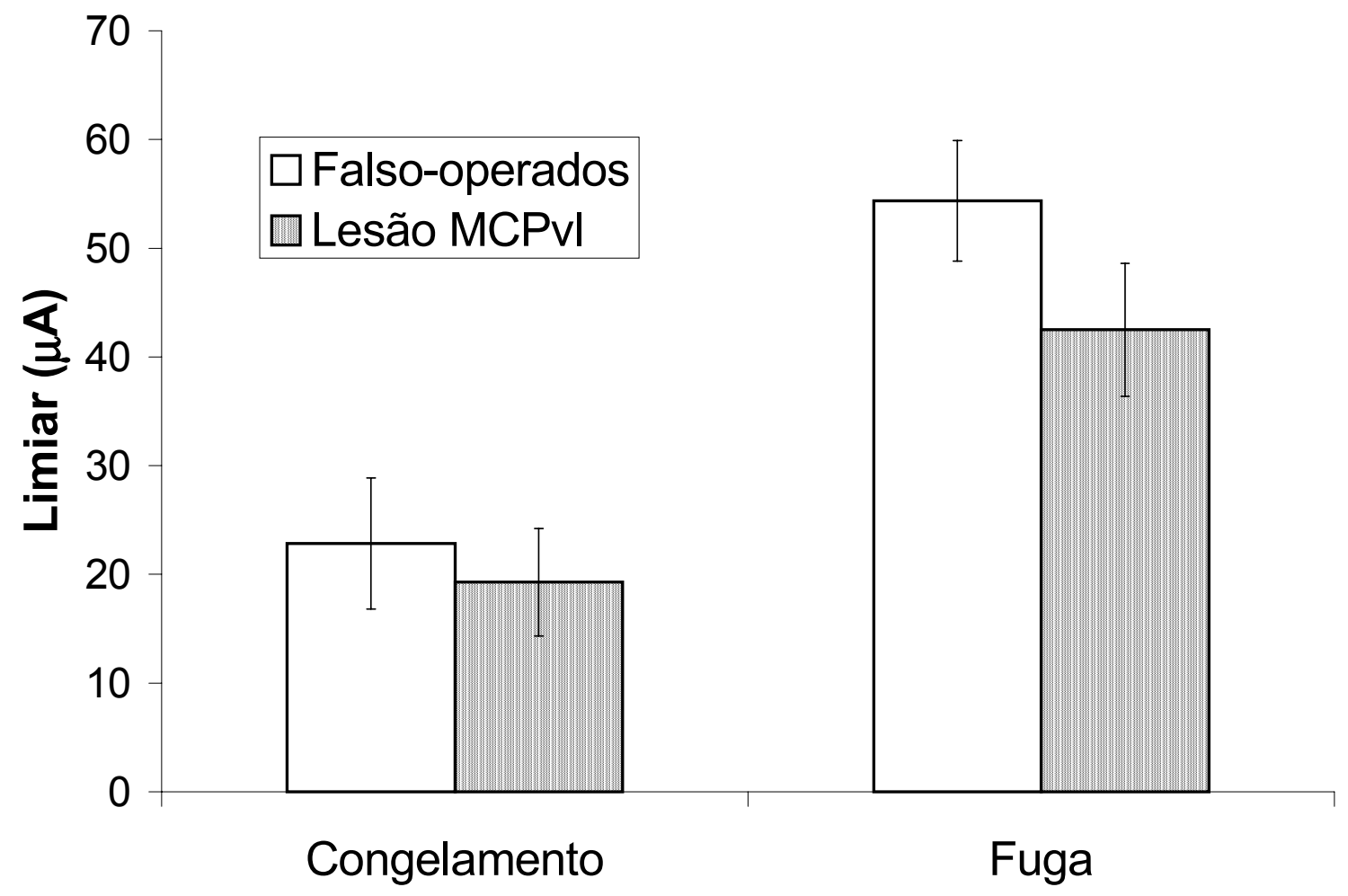

Figura 23. Limiares aversivos (média \pm E.P.M.) determinados durante a estimulação elétrica da MCPdl. $\mathrm{N}=8$ para os limiares de fuga, $\mathrm{N}=7$ para os limiares de congelamento. 


\section{Choque nas patas}

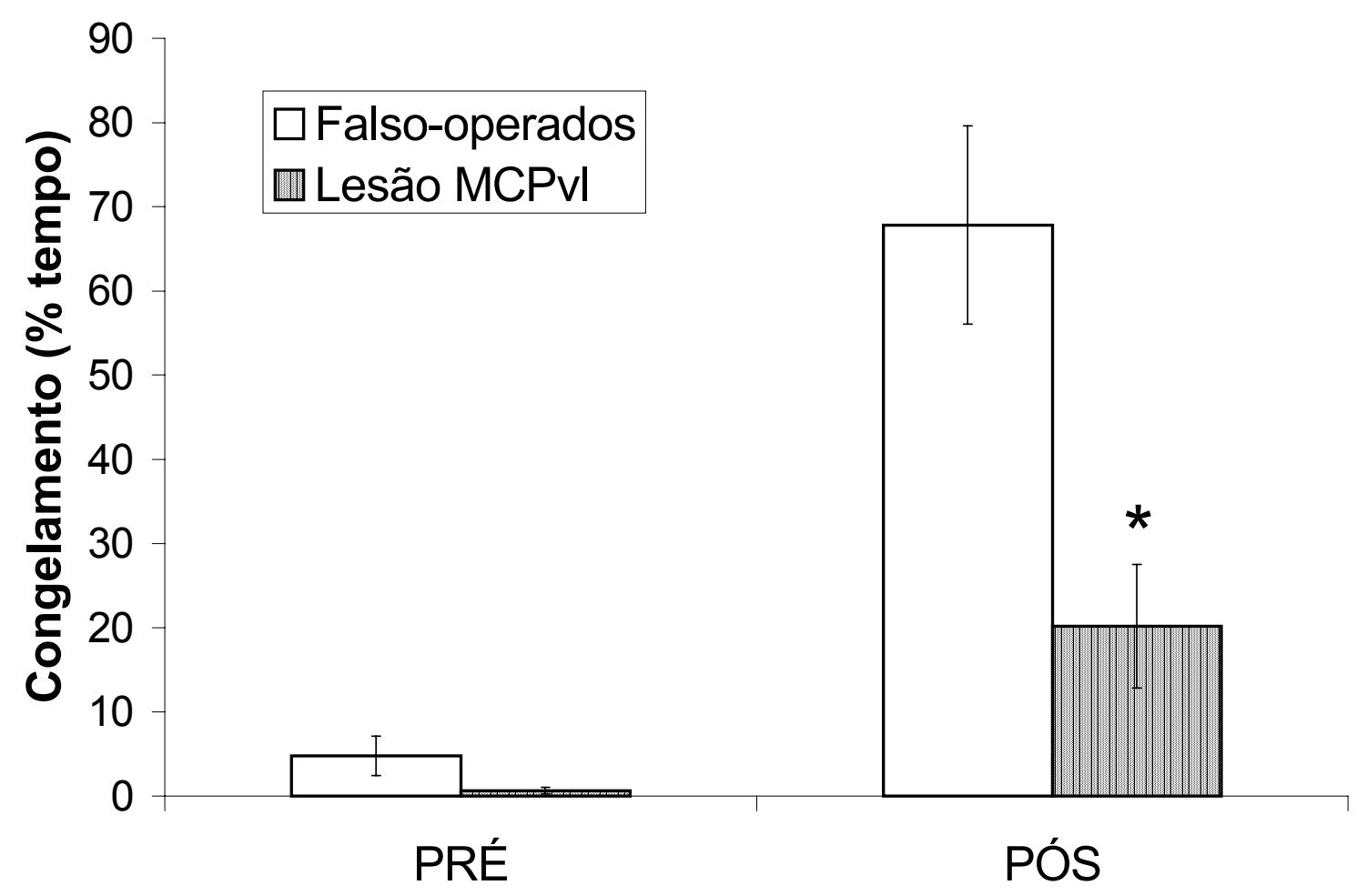

Figura 24. Percentagem de tempo (média \pm E.P.M.) de congelamento durante 6 min. No dia do treinamento ratos receberam 5 choques nas patas $(5 \mathrm{~s}, 1 \mathrm{~mA}, 60 \mathrm{~s}$ entre cada apresentação). PRÉ representa a linha de base e PÓS a sessão de teste $24 \mathrm{~h}$ depois do condicionamento. $\mathrm{N}=8$ para ambos os grupos. ${ }^{*} p<0,05$ entre os grupos lesado e falso-operado, por meio do teste t de Student. 
pletamente o congelamento (Fig. 24, colunas escuras), visto que os animais lesados congelaram significativamente mais na sessão 24 h após o choque do que durante a linha de base $(\mathrm{t}=2,71 ; p<0,05 ; \mathrm{gl}=7)$.

Finalmente, a quantificação da atividade locomotora medida na arena mostrou um aumento significativo $(\mathrm{t}=2,86 ; p<0,05 ; \mathrm{gl}=14)$ para o grupo lesado na MCPvl em relação ao grupo falso-operado (137.50 $\pm 16,69$ nos lesionados contra $77,13 \pm 12,88$ nos falso-operados, figura 25).

\section{Experimento 2- Estimulação química da MCPdl x lesão da MCPvl}

A figura 26 apresenta a média ( \pm EPM) do congelamento e fuga provocados pela microinfusão de semicarbazida na dIPAG em animais falso-operados ou lesados na MCPvl. Os resultados indicam que a lesão da MCPvl não tem efeito sobre comportamento defensivo provocado pela estimulação da MCPdl através de semicarbazida, para as a resposta de congelamento $(\mathrm{t}=0,38 ; p>0,05 ; \mathrm{gl}=16)$ ou de fuga $(\mathrm{t}=0,10 ; p>0,05 ; \mathrm{gl}=16)$. 


\section{Cruzamentos}

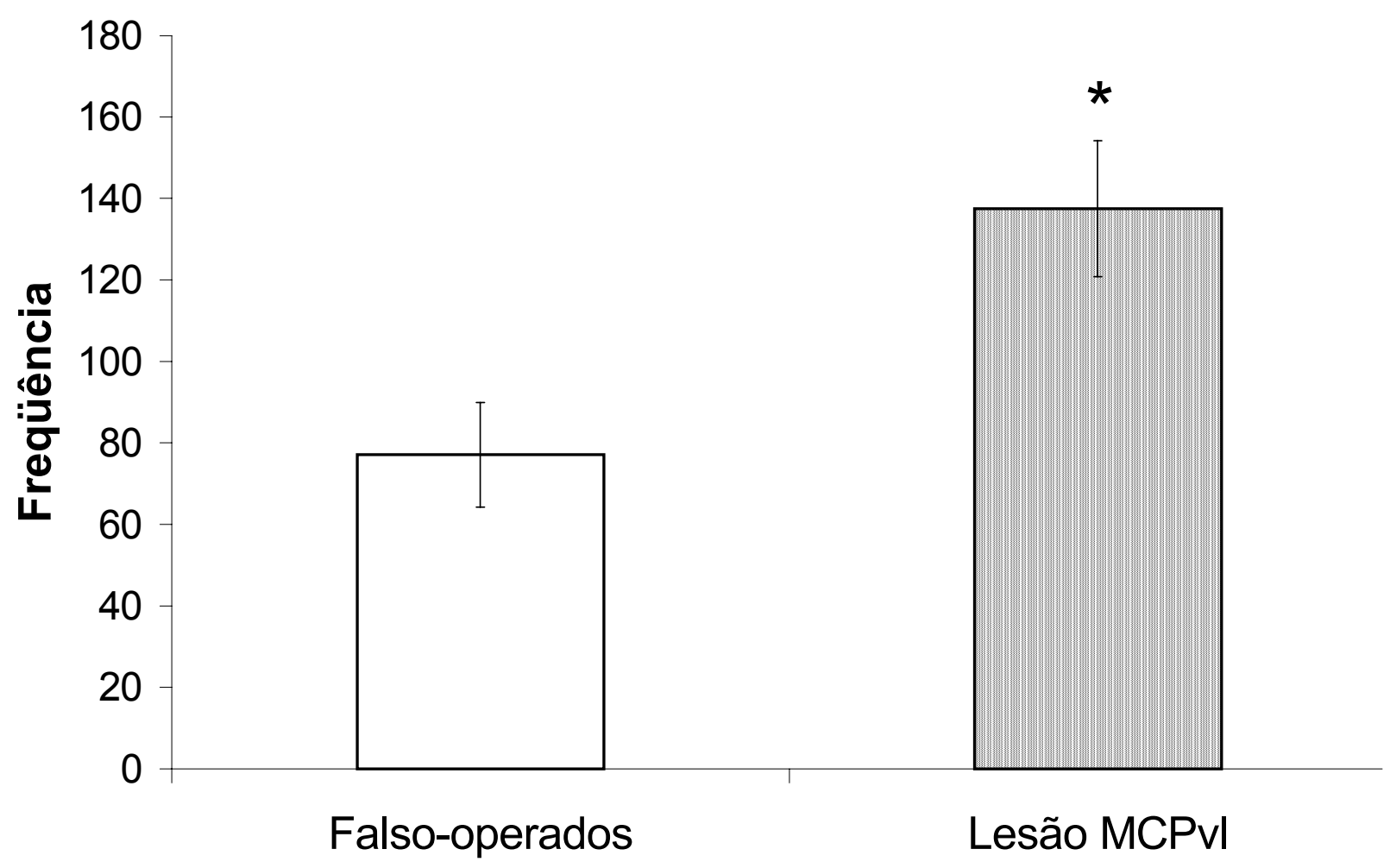

Figura 25. Número de cruzamentos (média \pm E.P.M.) medidos na arena durante os 6 min anteriores à estimulação elétrica da MCPdl. $\mathrm{N}=8$ para ambos os grupos. ${ }^{*} p<0,05$ entre os grupos lesado e falso-operado, por meio do teste $t$ de Student. 


\section{Semicarbazida}

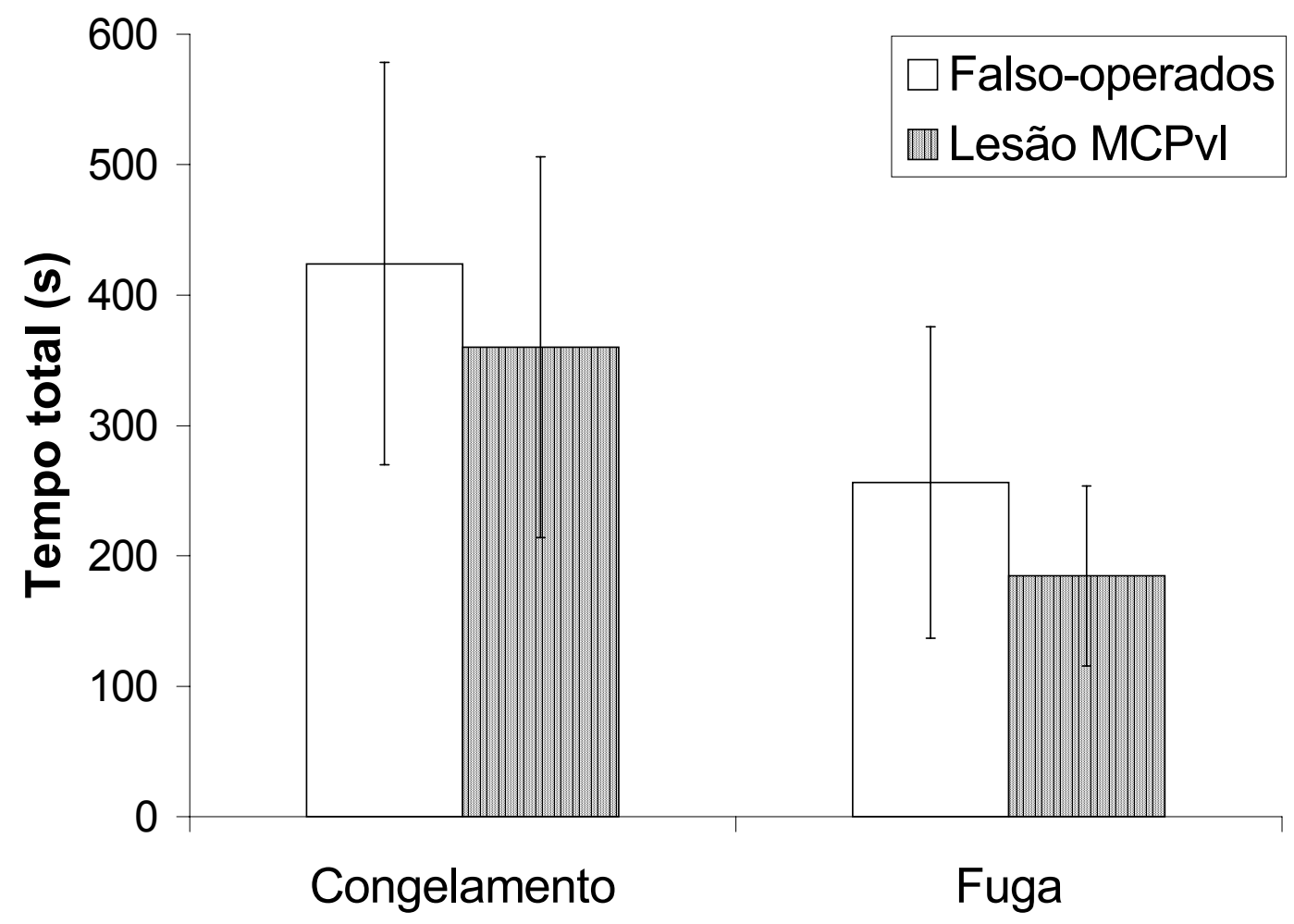

Figura 26. Tempo total (média \pm E.P.M.) de congelamento e fuga induzidos por microinjeção de semicarbazida $(8,0 \mu \mathrm{g} / 0,2 \mu \mathrm{l})$ na MCPdl. $\mathrm{N}=9$ para ambos os grupos. 
Discussão 
Os presentes resultados mostram que a mesma lesão da MCPvl que reduz marcadamente a resposta de congelamento a um contexto previamente associado com choque nas patas não é capaz de mudar o limiar de corrente elétrica que provoca congelamento e fuga na MCPdl ou o congelamento e fuga provocados pela estimulação de corpos neuroniais da MCPdl através de mediadores químicos.

O primeiro resultado está em total concordância com resultados anteriormente apresentados (De Oca et al., 1998; Fanselow, 1991; Fanselow et al., 1995; Kim et al., 1993; LeDoux et al., 1988) e sublinha o papel crítico da MCPvl no congelamento condicionado. Assim como foi relatado nesses estudos, no entanto, a lesão da MCPvl não aboliu completamente o congelamento condicionado, antes o atenuou, o que sugere que o congelamento não dependa completamente da MCPVl. As presentes lesões foram mais abrangentes do que as relatadas em Fanselow (1991) e Kim et al. (1993) e menores do que as lesões eletrolíticas de De Oca et al. (1998) e excitotóxicas de LeDoux et al. (1988). As lesões destes dois últimos estudos incluíram toda a MCP caudal, e mesmo assim levaram aos mesmos resultados. Isto sugere que a lesão parcial do tecido adjacente à $\mathrm{MCPvl}(\mathrm{CnF}$, MCPI, DR), bem como a lesão de fibras de passagem, não influenciou os resultados aqui relatados.

O congelamento condicionado, atenuado após a lesão da MCPVl, parece depender de uma projeção direta do CeA para esta subdivisão da MCP (Rizvi et al., 1995; Carrive et al., 2000; LeDoux et al., 1988). Além de participar da mediação das respostas de defesa a estímulos condicionados (LeDoux, 1995), alguns resultados também sugerem que a amígdala esteja envolvida no controle de respostas de defesa a estímulos incondicionados modais, como um som intenso (Bellgowan e Helmstetter, 1996), luz intensa (Walker e Davis, 1997) 
ou um gato sedado (Blanchard e Blanchard, 1972). Isto também vale para a MCPvl, cuja lesão atenua respostas incondicionadas ao som intenso (Bellgowan e Helmstetter, 1996) e à presença de um gato (De Oca et al., 1998). O que há em comum em todos estes trabalhos é a presença de um sinal de perigo potencial, e a ausência de perigo imediato. Mesmo De Oca et al. (1998) não relataram a ocorrência de tentativas de fuga em face ao predador em nenhum dos animais. No mesmo estudo, não houve contato físico do predador com a presa, o que também descarta a possibilidade de que imobilidade tônica tenha sido induzida. Tudo isso sugere que, naquele trabalho, apenas perigo potencial foi observado. Devido a estes resultados, consideramos que a via amígdala-MCPvl não só medeia a expressão do medo condicionado, mas todas as respostas defensivas ao perigo potencial, condicionadas e incondicionadas.

Por outro lado, o congelamento e a fuga provocados pela estimulação da MCPdl independem da integridade da MCPvl. Relatos anteriores já haviam indicado a ocorrência de congelamento provocado pela estimulação elétrica (Brandão et al., 1982) ou química (Bandler et al., 1985) desta subdivisão, acompanhando a resposta de fuga. De fato, foi também relatado que a lesão da MCPvl não afetou a resposta de congelamento induzida por estimulação elétrica do colículo inferior, outra estrutura envolvida na organização das reações defensivas (Maisonnette et al., 1996). Portanto, parece que existem ao menos dois circuitos neurais independentes subjacentes ao comportamento defensivo: um mediado pela MCPvl e outro independente. É possível que a resposta de congelamento gerada na MCPdl represente uma resposta defensiva distinta da mediada pela MCPvl (Fanselow, 1991; Fanselow et al., 1995; De Oca et al., 1998). 
Usando um procedimento distinto do descrito por De Oca et al. (1998), ao expor seus animais ao predador, Canteras \& Goto (1999) observaram a ocorrência tanto de congelamento quanto de fuga, e um aumento da expressão da proteína Fos em toda a MCP, preferencialmente na MCPdl. Isto é semelhante ao que é observado durante a estimulação química da MCPdl, que também causa congelamento e fuga, e sugere a presença de perigo imediato. Em um estudo semelhante (Canteras et al., 1997), o mesmo procedimento causou forte expressão Fos no PMd, um núcleo do hipotálamo que projeta direta e preferencialmente para a MCPdl (Canteras \& Swanson, 1992). A lesão do PMd, por outro lado, aboliu ambas as respostas (Canteras et al., 1997). Outros núcleos do hipotálamo também foram implicados na mediação dos comportamentos de defesa, e também estes se comunicam preferencialmente com a MCPdl (Canteras, 2002). Tudo isto é coerente com a hipótese de que a via Hipotálamo-MCPdl é responsável pela mediação das respostas de defesa ao perigo imediato.

As vias descendentes de ambas subdivisões (MCPdl e MCPvl) para o corno ventral da medula espinhal incluem os núcleos caudais da rafe (Holstege \& Kuypers, 1987). Enquanto a via que parte da MCPdl usa o núcleo cuneiforme como relé (Dean et al., 1988; Cowie e Holstege, 1992; Keay \& Bandler, 2001), a da MCPvl é direta (Hermann et al., 1997). A estimulação de neurônios na região destes núcleos provoca imobilidade (Morgan \& Whitney, 2000), o que novamente é compatível com o conceito de que tanto a MCPdl quanto a MCPvl podem mediar respostas de imobilidade.

Talvez o congelamento mediado pela MCPdl seja melhor compreendido como parte de uma estratégia de fuga observada comumente em várias espécies. Ratos, baratas e outros animais intercalam a fuga com a imobilidade quando são ameaçados por predado- 
res. O congelamento intercalado com a fuga torna mais difícil prever em que lugar do espaço o animal estará no momento seguinte, e portanto dificulta sua interceptação e captura. Além disso, como já foi reconhecido por vários autores, o congelamento também diminui a probabilidade da presa ser detectada após entrar no campo visual do predador. O primeiro exemplo sugere uma estratégia de defesa ao perigo imediato; o segundo, ao perigo potencial, já que o predador ainda não detectou ou anda não decidiu atacar a presa.

Entretanto, em algumas espécies, o perigo imediato também é capaz de provocar respostas de imobilidade pura, como no caso da imobilidade tônica. Esta resposta é mediada pela MCPvl (Monassi et al., 1997, 1999) e antagonizada pela MCPdl (Monassi et al., 1997), pelo núcleo central da amígdala (Leite-Panissi et al., 2002) e pelo hipotálamo medial (de Oliveira, 1997). Para que a imobilidade tônica aconteça, são necessários inversão postural e contenção dos movimentos, o que requer primariamente informação tátil e proprioceptiva, contrariamente ao congelamento e à fuga, que são provocados na natureza por estímulos modais e nociceptivos. Isto sugere que o substrato neural da imobilidade tônica seja substancialmente diferente do responsável pelo congelamento e pela fuga.

Finalmente, nossos resultados também revelam que a lesão da MCPvl por si só é capaz de aumentar a atividade locomotora dos animais no campo aberto. Isto é compatível com a presumida mediação pela MCPvl das respostas de imobilidade não acompanhadas de fuga (congelamento ao perigo potencial, quiescência e imobilidade tônica), e sugere que esta subdivisão exerce algum tipo de inibição tônica sobre os níveis de atividade basal do animal. Esta é a única subdivisão da MCP que projeta para o DR (Sakai et al., 1977; Kalén et al., 1985), que por sua vez é a principal fonte de aferências serotonérgicas para a MCPdl (Beitz et al., 1986). Boa parte dessas projeções são inibitórias (Stezhka e Lovick, 
1994), e agem através da serotonina (Lovick, 1994), que interfere com a fuga provocada pela estimulação da MCP dorsal (Schütz et al., 1985). Ou seja, através do DR, a MCPvl poderia modular a atividade da MCPdl de forma a inibir respostas ativas ao perigo. 
Conclusões 
1) O congelamento provocado por pistas contextuais previamente associadas ao choque nas patas depende da integridade da MCPvl.

2) O congelamento provocado pela estimulação elétrica ou química da MCPdl não depende da integridade da MCPvl, e pode ser provocado mesmo após sua lesão.

3) A lesão da MCPvl provoca um aumento na atividade locomotora espontânea, e sugere que esta subdivisão participa de um mecanismo de inibição tônica deste comportamento.

4) O congelamento mediado pela MCPdl provavelmente faz parte de uma estratégia de defesa ao perigo imediato.

5) O congelamento mediado pela MCPvl provavelmente faz parte de uma estratégia de defesa ao perigo potencial. 


\section{Resumo}


O congelamento a um contexto previamente associado ao choque nas patas é atenuado pela lesão da matéria cinzenta periaquedutal ventrolateral (MCPvl). Por outro lado, a estimulação elétrica ou microinjeção de compostos que diminuem a neurotransmissão GABAérgica na matéria cinzenta dorsolateral (MCPdl) provocam congelamento e fuga. $\mathrm{O}$ presente estudo examinou a possibilidade deste congelamento provocado pela estimulação da MCPdl ser resultado da ativação indireta da MCPvl. Ratos com lesão da MCPvl ou falsooperados foram eletricamente estimulados na MCPdl para a aferição dos limiares de resposta para o congelamento e a fuga. Os mesmos animais foram também submetidos ao condicionamento aversivo ao contexto através de choque nas patas, visando a validação de nossas condições experimentais. Um segundo grupo de ratos lesados e falso-operados receberam microinjeções de semicarbazida, um bloqueador da síntese do GABA, na MCPdl. Os resultados mostram que a lesão da MCPvl atenua o congelamento condicionado ao contexto, mas é ineficaz em alterar os efeitos da estimulação elétrica ou química da MCPdl sobre o congelamento e a fuga. A MCPvl é o alvo preferencial do núcleo central da amígdala na MCP, enquanto que a MCPdl recebe aferências principalmente dos núcleos do hipotálamo relacionados à defesa. Estas evidências são coerentes com a participação da MCPvl nas respostas de defesa ao perigo potencial, e da MCPdl ao perigo imediato. 
Abstract 
Freezing to a context previously associated to footshock is attenuated by ventrolateral periaqueductal gray (vIPAG) lesion. Moreover, electrical stimulation or microinfusion of compounds that interfere with GABA neurotransmission in the dorsolateral periaqueductal gray (dIPAG) provoke freezing and escape. The present study examined the possibility of this freezing being the result of an indirect activation of vIPAG through dIPAG stimulation. Rats bearing vIPAG or sham lesions were electrically stimulated at dIPAG sites to have their freezing and escape threshold currents measured. The same animals were also submitted to a contextual fear-conditioning paradigm through footshock to validate our experimental setting. A second group of vIPAG- and sham-lesion rats received infusions of semicarbazide, a GABA-synthesis blocker, in the MCPdl. The results obtained show that vIPAG lesions do attenuate conditioned freezing, but are ineffective against dIPAG-stimulation freezing and escape. The vIPAG is the main PAG target to central nucleus of amygdala projections, while the dIPAG receives afferents primarily from hypothalamic nuclei related to defense. This evidence is coherent with vIPAG mediating responses to potential danger, while dIPAG would be more related to immediate danger. 


\section{Referências}


ANTONIADIS, E.A.; MCDONALD, R.J. Amygdala, hippocampus, and unconditioned fear.

Experimental Brain Research, v.138, p.200-9, 2001.

AVANZI, V.; BRANDÃO, M.L. Activation of somatodendritic 5-HT1A autoreceptors in the median raphe nucleus disrupts the contextual conditioning in rats. Behavioural Brain Research, v.126, p.175-84, 2001.

BANDLER, R. Brain mechanisms of aggression as revealed by electrical and chemical stimulation: suggestion of a central role for the midbrain periaqueductal grey region. In: Epstein, A.N.; Morrison, R. (Eds.), Progress in Psychobiology and Physiological Psychology. New York: Academic, 1987.

BANDLER, R.; DEPAULIS, A.; VERGNES, M. Identification of midbrain neurones mediating defensive behaviour in the rat by microinjections of excitatory amino acids. Behavioural Brain Research, v.15, p.107-119,1985.

BANDLER, R.; CARRIVE, P.; ZHANG, S.P. Integration of somatic and autonomic reactions within the midbrain periaqueductal grey: viscerotopic, somatotopic and functional organization. Progress in Brain Research, v.87, p.269-305, 1991.

BARBARESI, P.; MANFRINI, E. Glutamate decarboxylase-immunoreactive neurons and terminals in the periaqueductal gray of the rat. Neuroscience, v.27, n.1, p.183-91, 1988. BARD, P. A diencephalic mechanism for the expression of rage with special reference to the sympathetic nervous system. American Journal of Physiology, v.84, n.3, p.490-515, 1928. 
BAXTER, B.L. Elicitation of emotional behavior by electrical or chemical stimulation applied at the same loci in cat mesencephalon. Experimental Neurology, v.21, p.1-10, 1968.

BEITZ, A.J. The midbrain periaqueductal gray in the rat. I. Nuclear volume, cell number, density, orientation, and regional subdivisions. Journal of Comparative Neurology, v.237, p.445-59, 1985.

BEITZ, A.J.; CLEMENTS, J.R.; MULLET, M.A.; ECKLUND, L.J. Differential origin of brainstem serotoninergic projections to the midbrain periaqueductal gray and superior colliculus of the rat. Journal of Comparative Neurology, v.250, p.498-509, 1986.

BELLGOWAN, P.S.F.; HELMSTETTER, F.J. Neural systems for the expression of hypoalgesia during nonassociative fear. Behavioral Neuroscience, v.110, n.4, p.727-36, 1996.

BESSON, J-M.; FARDIN, V.; OLIVÉRAS, J-L. Analgesia produced by stimulation of the periaqueductal gray matter: true antinociceptive effects versus stress effects. In: Depaulis, A.; Bandler, R. (Eds.), The midbrain periaqueductal gray matter. New York: Plenum, 1991.

BLANCHARD, D.C.; BLANCHARD, R.J. Innate and conditioned reactions to threat in rats with amygdaloid lesions. Journal of Comparative and Physiological Research, v.81, n.2, p.281-90, 1972.

BLANCHARD, D.C.; BLANCHARD, R.J. Ethoexperimental approaches to the biology of emotion. Annual Review of Psychology, v.39, 43-68, 1988. 
BLANCHARD, D.C.; WILLIAMS, G.; LEE, E.M.C.; BLANCHARD, R.J. Taming of wild Rattus norvegicus by lesions of the mesencephalic central gray. Physiological Psychology, v.9, n.2, p.157-63, 1981.

BLOMQVIST, A.; CRAIG, A.D. (1991). Organization of spinal and trigeminal input to the PAG. In: Depaulis, A.; Bandler, R. (Eds.), The midbrain periaqueductal gray matter. New York: Plenum, 1991.

BRANDÃO, M.L.; DE AGUIAR, J.C.; GRAEFF, F.G. GABA mediation of the anti-aversive action of minor tranquilizers. Pharmacology, Biochemistry \& Behavior, v.16, p.397402, 1982.

BUMA, P.; VEENING, J.; HAFMANS, T.; JOOSTEN, H.; NIEUWENHUYS, R. Ultrastructure of the periaqueductal grey matter of the rat: an electron microscopical and horseradish peroxidase study. Journal of Comparative Neurology, v.319, p.519-35, 1992.

CAMERON, A.A.; KHAN, I.A.; WESTLUND, K.N.; CLIFFER, K.D.; WILLIS, W.D. The efferent projections of the periaqueductal gray in the rat: a phaseolus vulgarisleucoagglutinin study. I. Ascending projections. Journal of Comparative Neurology, v.351, p568-84, 1995.

CANTERAS, N.S. The medial hypothalamic defensive system: hodological organization and functional implications. Pharmacology, Biochemistry and Behavior, v.71, p.48191, 2002. 
CANTERAS, N.S.; CHIAVEGATTO, S.; RIBEIRO DO VALLE, L.E.; SWANSON, L.W. Severe reduction of rat defensive behavior to a predator by discrete hypothalamic chemical lesions. Brain Research Bulletin, v.44, n.3, p.297-305, 1997.

CANTERAS, N.S.; GOTO, M. Fos-like immunoreactivity in the periaqueductal gray of rats exposed to a natural predator. Neuroreport, v.10, p.413-18, 1999.

CANTERAS, N.S.; SWANSON, L.W. The dorsal premammilary nucleus: an unusual component of the mammilary body. Proceedings of the National Academy of Sciences, v.89, p.10089-93, 1992.

CARRIVE, P. Functional organization of PAG neurons controlling regional vascular beds. In: Depaulis, A.; Bandler, R. (Eds.), The midbrain periaqueductal gray matter. New York: Plenum, 1991.

CARRIVE, P. The periaqueductal gray and defensive behaviour: functional representation and neuronal organization. Behavioural Brain Research, v.58, p.27-47, 1993.

CARRIVE, P. Conditioned fear to environmental context: cardiovascular and behavioral components in the rat. Brain Research, v.858, p.440-5, 2000.

CARRIVE, P.; BANDLER, R.; DAMPNEY, R.A.L. Somatic and autonomic integration in the midbrain of the unanesthetized descerebrate cat: a distinctive pattern evoked by excitation of neurones in the subtentorial portion of the midbrain periaqueductal grey. Brain Research, v.483, p.251-8, 1989. 
CARRIVE, P.; DAMPNEY, R.A.L.; BANDLER, R. Excitation of neurones in a restricted portion of the midbrain periaqueductal grey elicits both the behavioral and cardiovascular components of the defence reaction in the unanaesthetized decerebrated cat. Neuroscience Letters, v.81, p.273-8, 1987.

CARRIVE, P.; LEE, J.; SU, A. Lidocaine blockade of amygdala output in fear conditioned rats reduces fos-expression in the ventrolateral periaqueductal gray. Neuroscience, v.95, n.4, p.1071-80, 2000.

CARRIVE, P.; LEUNG, P.; HARRIS, J.; PAXINOS, G. Conditioned fear to context is associated with increased fos expression in the caudal ventrolateral region of the midbrain periaqueductal gray. Neuroscience, v.78, n.1, p.165-77, 1997.

CHEN, S.; SU, H.-S. Afferent connections of the thalamic paraventricular and parataenial nuclei in the rat - a retrograde tracing study with iontophoretic application of fluorogold. Brain Research, v.522, p.1-6, 1990.

CLEMENT, C.I.; KEAY, K.A.; OWLER, B.K.; BANDLER, R. Common patterns of increased and decreased Fos expression in midbrain and pons evoked by noxious deep somatic and noxious visceral manipulations in the rat. Journal of Comparative Neurology, v.366, p.495-515, 1996.

CLEMENTS, J.R.; BEITZ, A.J.; FLETCHER, T.F.; MULLET, M.A. Immunocytochemical localization of serotonin in the rat periaqueductal gray: a quantitative light and electron mi- 
croscopic study. Journal of Comparative Neurology, v.236, p.60-70, 1985.

CLEMENTS, J.R.; MADL, J.E.; JOHNSON, R.L.; LARSON, A.A.; BEITZ, A.J. Localization of glutamate, glutaminase, aspartate and aspartate aminotransferase in the rat midbrain periaqueductal gray. Experimental Brain Research, v.67, p.594-602, 1987.

COIMBRA, N.C.; BRANDÃO, M.L. GABAergic nigro-collicular pathways modulate the defensive behavior elicited by midbrain tectum stimulation. Behavioural Brain Research, v.59, p.131-9, 1993.

CONTI, F.; BARBARESI, P.; FABRI, M. Cytochrome oxidase histochemistry reveals regional subdivisions in the rat periaqueductal gray matter. Neuroscience, v.24, n.2, p.629-33, 1988.

COWIE, R.J.; HOSTEGE, G. Dorsal mesencephalic projections to pons, medulla, and spinal cord in the rat: limbic and non-limbic components. Journal of Comparative Neurology, v.319, p.536-59, 1992.

DE OCA, B.M.; DECOLA, J.P.; MAREN, S.; FANSELOW, M.S. Distinct regions of the periaqueductal gray are involved in the acquisition and expression of defensive responses. Journal of Neuroscience, v.18, n.9, p.3426-32, 1998.

DE OLIVEIRA, L.; HOFFMANN, A.; MENESCAL-DE-OLIVEIRA, L. Participation of the medial and anterior hypothalamus in the modulation of tonic immobility in guinea pigs. Physiology \& Behavior, v.62, n.5, p.1171-8, 1997. 
DE OLIVEIRA, R.W.; DEL BEL, E.A.; GUIMARÃES, F.S. Behavioral and c-fos expression changes induced by nitric oxide donors microinjected into the dorsal periaqueductal gray. Brain Research Bulletin, v.51, p.457-64, 2000.

DEAN, P.; REDGRAVE, P.; MITCHELL, I.J. Organisation of efferent projections from superior colliculus to brainstem in rat: evidence for functional output channels. Progress in Brain Research, v.75, p.27-36, 1988.

DEPAULIS, A.; KEAY, K.A.; BANDLER, R. Quiescence and hyporeactivity evoked by activation of cell bodies in the ventrolateral periaqueductal gray of the rat. Experimental Brain Research, v.99, p.75-83, 1994.

DI SCALA, G.; MANA, M.J.; JACOBS, W.J.; PHILLIPS, A.G. Evidence of Pavlovian conditioned fear following electrical stimulation of the periaqueductal gray in the rat. Physiology \& Behavior, v.40, p.55-63. 1987.

DIELENBERG, R.A.; HUNT, G.E.; MCGREGOR, I.S. When a rat smells a cat: the distribution of fos immunoreactivity in rat brain following exposure to a predatory odor. Neuroscience, v.104, n.4, p.1085-97, 2001.

FANSELOW, M.S. The midbrain periaqueductal gray as a coordinator of action in response to fear and anxiety. In: Depaulis, A.; Bandler, R. (Eds.), The midbrain periaqueductal gray matter. New York: Plenum, 1991.

FANSELOW, M.S.; DECOLA, J.P.; DE OCA, B.; LANDEIRA-FERNANDEZ, J. Ventral and 
dorsolateral regions of the midbrain periaqueductal gray (PAG) control different stages of defensive behavior: dorsolateral PAG lesions enhance the defensive freezing produced by massed and immediate shock. Aggressive Behavior, v.21, p.63-77, 1995.

FLOYD, N.S.; PRICE, J.L.; FERRY, A.T.; KEAY, K.A.; BANDLER, R. Orbitomedial prefrontal cortical projections to distinct longitudinal columns of the periaqueductal gray in the rat. Journal of Comparative Neurology, v.422, p.556-78, 2000.

GRAEFF, F.G. Neuroanatomy and neurotransmitter regulation of defensive behaviors and related emotions in mammals. Brazilian Journal of Medical and Biological Research, v.27, p.811-29, 1994.

HERMANN, D.M.; LUPPI, P.-H.; PEYRON, C.; HINCKEL, P.; JOUVET, M. Afferent projections to the rat nuclei raphe magnus, raphe pallidus and reticularis gigantocellularis pars a demostrated by iontophoretic application of choleratoxin (subunit b). Journal of Chemical Neuroanatomy, v.13, p.1-21, 1997.

HESS, W.R.; BRÜGGER, M. Das subkortikale Zentrum der affektiven Abwehrreaktion. Helvetica Physiologica Acta, v.1, p.33-52, 1943.

HOLSTEGE, J.C.; KUYPERS, H.G.J.M. Brainstem projections to spinal motoneurons: an update. Neuroscience, v.23, n.3, p.809-21, 1987.

HOSOBUCHI, Y.; ADAMS, J.E.; LINCHITZ, R. Pain relief by electrical stimulation of the central gray matter in humans and its reversal by naloxone. Science, v.197, p.183-97, 1977. 
HUNSPERGER, R.W. Affektreaktionen auf elektrische reizung in hirnstamm der katze.

Helvetica Physiologica Acta, v.14, p.70-92, 1956.

HUNSPERGER, R.W. Comportements affectifs provoqués par la stimulation électrique du tronc cérébral et du cerveau antérieur. Journal de Physiologie, v.55, p.45-97, 1963.

KALÉN, P.; KARLSON, M.; WIKLUND, L. Possible excitatory amino acid afferents to nucleus raphe dorsalis of the rat investigated with retrograde wheat germ agglutinin and D$\left[{ }^{3} \mathrm{H}\right]$ aspartate tracing. Brain Research, v.360, p.285-97, 1985.

KEAY, K.A.; BANDLER, R. Anatomical evidence for segregated input from the upper cervical spinal cord to functionally distinct regions of the midbrain periaqueductal grey region in the cat. Neuroscience Letters, v.139, p.143-8, 1992.

KEAY, K.A.; BANDLER, R. Deep and superficial noxious stimulation increases Fos-like immunoreactivity in different regions of the midbrain periaqueductal grey of the rat. Neuroscience Letters, v.154, p.23-6, 1993.

KEAY, K.A.; BANDLER, R. Parallel circuits mediating distinct emotional coping reactions to different types of stress. Neuroscience and Biobehavioral Reviews, v.25, p.66978, 2001.

KEAY, K.A.; BANDLER, R. Distinct central representations of inescapable and escapable pain: observations and speculation. Experimental Physiology, v.87, n.2, p.275-9, 2002. 
KEAY, K.A.; CLEMENT, C.I.; DEPAULIS, A.; BANDLER, R. Different representations of inescapable noxious stimuli in the periaqueductal gray and upper cervical spinal cord of freely moving rats. Neuroscience Letters, v.313, p.17-20, 2001.

KIM, J.J.; RISON, R.A.; FANSELOW, M.S. Effects of amygdala, hippocampus, and periaqueductal gray lesions on short- and long-term contextual fear. Behavioral Neuroscience, v.107, n.6, p. 1093-8, 1993.

KOLMAC, C.I.; MITROFANIS, J. Patterns of brainstem projection to the thalamic reticular nucleus. Journal of Comparative Neurology, v.396, p.531-43, 1998.

KRIEGER, J.E.; GRAEFF, F.G. Defensive behavior and hypertension induced by glutamate in the midbrain central gray of the rat. Brazilian Journal of Medical and Biological Research, v.18, p.61-7, 1985.

KROUT, K.E.; LOEWY, A.D. Periaqueductal gray matter projections to midline and intralaminar thalamic nuclei of the rat. Journal of Comparative Neurology, v.424, p.111-41, 2000.

LEDOUX, J.E. Emotion circuits in the brain. Annual Review of Neuroscience, v.23, p.155$84,2000$.

LEDOUX, J.E.; IWATA, J.; CICHETTI, P.; REIS, D.J. Different projections of the central amygdaloid nucleus mediate autonomic and behavioral correlates of conditioned fear. Journal of Neuroscience, v.8, n.7, p.2517-29, 1988.

LEE, J.-H.; BEITZ, A.J. The distribution of brain-stem and spinal cord nuclei associated with 
different frequencies of eletroacupunture analgesia. Pain, v.52, p.11-28.

LEITE-PASSINI, C.R.A.; MENESCAL-DE-OLIVEIRA, L. Central nucleus of the amygdala and the control of tonic immobility in guinea pigs. Brain Research Bulletin, v.58, n.1, p.13-9, 2002.

LOVICK, T.A. Influence of the dorsal and median raphe nuclei on neurons in the periaqueductal gray matter: role of 5-hydroxytryptamine. Neuroscience, v.59, n.4, p.993-1000, 1994. MAISONETTE, S.S.; KAWASAKI, M.C.; COIMBRA, N.C.; BRANDÃO, M.L. Effect of lesions of amygdaloid nuclei and substantia nigra on aversive responses induced by electrical stimulation of the inferior collicurus. Brain Research Bulletin, v.40, n.2, p.93-8, 1996. MAGOUN, H.W.; ATLAS, D.; INGERSOLL, E.H.; RANSON, S.W. Associated facial, vocal and respiratory components of emotional expression. Journal of Neurological Psychopathology, v.17, p.241-55, 1937.

MANTYH, P.W. The midbrain periaqueductal gray in the rat, cat and monkey: a nissl, weiss and golgi analysis. Journal of Comparative Neurology, v.204, p.349-63, 1982a.

MANTYH, P. W. Forebrain projections to the periaqueductal gray in the monkey, with observations in the cat and rat. Journal of Comparative Neurology, v.206, p.146-58, 1982b. MANTYH, P.W. Connections of the midbrain periaqueductal gray in the monkey. I. Ascending efferent projections. Journal of Neuroscience, v.49, n.3, p.567-81, 1983a.

MANTYH, P.W. Connections of the midbrain periaqueductal gray in the monkey. II. Descend- 
ing efferent projections. Journal of Neuroscience, v.49, n.3, p.582-94, $1983 \mathrm{~b}$.

MARCINKIEWICZ, M.; MORCOS, R.; CHRÉTIEN, M. CNS connections with the median raphe nucleus: retrograde tracing with WGA-apoHRP-gold complex in the rat. Journal of Comparative Neurology, v.289, p.11-35, 1989.

MAREN, S. Neurotoxic basolateral amygdala lesions impair learning and memory but not the performance of conditioned fear in rats. Journal of Neuroscience, v.19, p.8696703, 1999.

MELZACK, R.; STOTLER, W.A.; LIVINGSTON, W.K. Effects of discrete brainstem lesions in cats on perception of noxious stimulation. Journal of Neurophysiology, v.21, p.35367, 1958.

MONASSI, C.R.; HOFFMAN, A.; MENESCAL-DE-OLIVEIRA, L. Involvement of the cholinergic system and periaqueductal gray matter in the modulation of tonic immobility in the guinea pig. Physiology \& Behavior, v.62, n.1, 53-9, 1997.

MONASSI, C.R.; LEITE-PASSINI, C.R.A.; MENESCAL-DE-OLIVEIRA, L. Ventrolateral periaqueductal gray matter and the control of tonic immobility. Brain Research Bulletin, v.50, n.3, p.201-8, 1999.

MORGAN, M.M.; CARRIVE, P. Activation of the ventrolateral periaqueductal gray reduces locomotion but not mean arterial pressure in awake, freely moving rats. Neuroscience, v.102, n.4, p.905-10, 2001. 
MORGAN, M.M.; DEPAULIS, A.; LIEBESKIND, J.C. Diazepam dissociates the analgesic and aversive effects of periaqueductal gray stimulation in the rat. Brain Research, v.423, p.395-8, 1987.

MORGAN, M.M.; WHITNEY, P.K. Immobility accompanies the antinociception mediated by the rostral ventromedial medulla of the rat. Brain Research, v.872, p.276-81, 2000.

MOUTON, L.J.; HOLSTEGE, G. The periaqueductal gray in the cat projects to lamina VIII and the medial part of lamina VII throughout the lenght of the spinal cord. Experimental Brain Research, v.101, p.253-64, 1994.

MURPHY, A.Z.; ENNIS, M.; RIZVI, T.A.; BEHBEHANI, M.M.; SHIPLEY, M.T. Fos expression induced by changes in arterial pressure is localized in distinct, longitudinally organized columns of neurons in the rat midbrain periaqueductal gray. Journal of Comparative Neuroanatomy, v.360, p.286-300, 1995.

NASHOLD, B.S., JR.; WILSON, W.P.; SLAUGHTER, D.G. Sensations evoked by stimulation in the midbrain of man. Journal of Neurosurgery, v.30, p.14-24, 1969.

NEWMAN, D.B.; HILEARY, S.K.; GINSBERG, C.Y. Nuclear terminations of corticonuclear fiber systems in rats. Brain, Behavior and Evolution, v.34, p.223-64, 1989.

ONSTOTT, D.; MAYER, B.; BEITZ, A.J. Nitric oxide synthase immunoreactive neurons anatomically define a longitudinal dorsolateral column within the midbrain periaqueductal gray of the rat: analysis using laser confocal microscopy. Brain Research, v.610, 317- 
24, 1993.

PAXINOS, G.; WATSON, C. The Rat Brain in Stereotaxic Coordinates, $3^{\text {rd }}$ ed. San Diego: Academic Press, 1997.

PRADO, W.A.; ROBERTS, M.H.T. An assessment of the antinociceptive and aversive effects of stimulating identified sites in the rat brain. Brain Research, v.340, p.219-28, 1985.

RAMPON, C.; LUPPI, P.H.; FORT, P.; PEYRON, C.; JOUVET, M. Distribution of glycine-immunoreactive cell bodies and fibers in the rat brain. Neuroscience, v.65, n.3, p.737$55,1996$.

REDGRAVE, P.; DEAN, P.; MITCHELL, I.J.; ODEKUNLE, A.; CLARK, A. The projection from superior colliculus to cuneiform area in the rat. I. Anatomical studies. Experimental Brain Research, v.72, p.611-25, 1988.

REYNOLDS, D.V. Surgery in the rat during electrical analgesia by focal brain stimulation. Science, v.164, p.444-5, 1969.

RISOLD, P.Y.; THOMPSON, R.H.; SWANSON, L.W. The structural organization of connections between hypothalamus and cerebral cortex. Brain Research Reviews, v.24, p.197-254, 1997.

RIZVI, T.A.; ENNIS, M.; BEHBEHANI, M.; SHIPLEY, M.T. Connections between the central nucleus of the amygdala and the midbrain periaqueductal gray: topography and reci- 
procity. Journal of Comparative Neurology, v.303, p.121-31, 1991.

RUIZ-TORNER, A.; OLUCHA-BORDONAU, F.; VALVERDE-NAVARRO, A.A.; MARTINEZSORIANO, F. The chemical architecture of the rat's periaqueductal gray based on acetilcholinesterase histochemistry: a quantitative and qualitative study. Journal of Chemical Neuroanatomy, v.21, p.295-312, 2001.

SANDNER, G.; DI SCALA, G.; ROCHA, B.; ANGST, M.J. C-fos immunoreactivity in the brain following unilateral electrical stimulation of the dorsal periaqueductal gray in freely moving rats. Brain Research, v.573, p.276-83, 1992.

SANDNER, G.; OBERLING, P.; SILVEIRA, M.C.; DI SCALA, G.; ROCHA, B.; BAGRI, A.; DEPOORTERE, R. What brain structures are active during emotion? Effects of brain stimulation elicited aversion on c-Fos immunoreactivity and behavior. Behavioural Brain Research, v.58, p.9-18, 1993.

SAKAI, K.; SALVERT, D.; TOURET, M.; JOUVET, M. Afferent connections of the nucleus raphe dorsalis in the cat as visualized by the horseradish peroxidase technique. Brain Research, v.137, p.11-35, 1977.

SCHENBERG, L.C.; COSTA, M.B.; BORGES, P.C.L.; CASTRO, F.S. Logistic analysis of the defense reaction induced by electrical stimulation of the rat mesencephalic tectum. Neuroscience and Biobehavioral Reviews, v.14, p.473-9, 1990.

SCHMITT, P.; CARRIVE, P.; DI SCALA, G.; JENCK, F.; BRANDÃO, M.; BAGRI, A.; MOREAU, 
J.-L.; SANDNER, G. A neuropharmacological study of the periventricular neural substrate involved in flight. Behavioural Brain Research, v.22, p.181-90, 1986.

SCHMITT, P.; ECLANCHER, F.; KARLI, P. Etude des systémes de renforcement négatif et de renforcement positif au niveau de la substance grise centrale chez le rat. Physiology \& Behavior, v.12, p.271-9, 1974.

SCHÜTZ, M.T.B.; DE AGUIAR, J.C.; GRAEFF, F.G. Anti-aversive role of serotonin in the dorsal periaqueductal gray matter. Psychopharmacology, v.85, p.340-5, 1985.

SEMENENKO, F.M.; LUMB, B.M. Projections of anterior hypothalamic neurones to the dorsal and ventral periaqueductal grey in the rat. Brain Research, v.582, p.237-45, 1992.

SHIPLEY, M.T.; MCLEAN, J.H.; BEHBEHANI, M.M. Heterogeneous distribution of neurotensinlike immunoreactive neurons and fibers in the midbrain periaqueductal gray of the rat. Journal of Neuroscience, v.7, n.7, p.2025-34, 1987.

SMITH, G.S.T.; SAVERY, D.; MARDEN, C.; COSTA, J.J.L.; AVERILL, S.; PRIESTLEY, J.V.; RATTRAY, M. Distribution of messenger RNAs encoding enkephalin, substance P, somatostatin, galanin, vasoactive intestinal polypeptide, neuropeptide $\mathrm{Y}$, and calcitonin gene-related peptide in the midbrain periaqueductal grey in the rat. Journal of Comparative Neurology, v.350, p.23-40, 1994.

STEZHKA, V.V.; LOVICK, T.A. Inhibitory and excitatory projections from the dorsal raphe nucleus to neurons in the dorsolateral periaqueductal gray matter in slices of midbrain 
maintained in vitro. Neuroscience, v.62, n.1, p.177-87, 1994.

TANIGUCHI, N.; MIYATA, M.; YACHIKU, S.; KANEKO, S.; YAMAGUCHI, S.; NUMATA, A. A study of micturition inducing sites in the periaqueductal gray of the mesencephalon. Journal of Urology, v.168, p.1626-31, 2002.

THORN, B.E.; APPLEGATE, L.; JOHNSON, S.W. Ability of periaqueductal gray subdivisions and adjacent loci to elicit analgesia and ability of naloxone to reverse analgesia. Behavioral Neuroscience, v.103, n.6, p.1335-9, 1989.

TOMAZ, C.; BRANDÃO, M.; BAGRI, A.; CARRIVE, P.; SCHMITT, P. Flight behavior induced by microinjection of GABA antagonists into periventricular structures in detelencephalated rats. Pharmacology, Biochemistry \& Behavior, v.30, p.337-42, 1988.

VAZDARJANOVA, A. Does the basolateral amygdala store memories for emotional events?

Trends in Neuroscience, v.23, p.345, 2000.

VERTES, R.P. A PHA-L analysis of ascending projections of the dorsal raphe nucleus in the rat. Journal of Comparative Neurology, v.313, p.643-68, 1991.

VIANNA, D.M.L.; GRAEFF, F.G.; BRANDÃO, M.L.; LANDEIRA-FERNANDEZ, J. Defensive freezing evoked by electrical stimulation of the periaqueductal gray: comparison between dorsolateral and ventrolateral regions. Neuroreport, v.12, n.18, p.4109-12, 2001a. VIANNA, D.M.L.; LANDEIRA-FERNANDEZ, J.; BRANDÃO, M.L. Dorsolateral and ventral 
regions of the periaqueductal gray matter are involved in distinct types of fear. Neuroscience \& Biobehavioral Reviews, v.25, p.711-9, 2001c.

VINCENT, S.R.; KIMURA, H. Histochemical mapping of the nitric oxide synthase in the rat brain. Neuroscience, v.46, n.4, p.755-84, 1992.

WALKER, D.L.; DAVIS, M. Double dissociation between the involvement of the bed nucleus of the stria terminalis and the central nucleus of the amygdala in startle increases produced by conditioned versus unconditioned fear. Journal of Neuroscience, v.17, n.23, p.9375-83, 1997.

WALLACE, K.J.; ROSEN, J.B. Predator odor as an unconditioned fear stimulus in rats: elicitation of freezing by trimethylthiazoline, a component of fox feces. Behavioral Neuroscience, v.114, n.5, p.912-22, 2000.

WILLIS, W.D.; WESTLUND, K.N. Neuroanatomy of the pain system and of the pathways that modulate pain. Journal of Clinical Neurophysiology, v.14, n.1, p.2-31, 1997.

YEZIERSKI, R.P. Spinomesencephalic tract: projections from the lumbosacral spinal cord of the rat, cat, and monkey. Journal of Comparative Neurology, v.267, p.131-46, 1988.

ZHANG, S.P.; BANDLER, R.; CARRIVE, P. Flight and immobility evoked by excitatory amino acid microinjection within distinct parts of the subtentorial midbrain periaqueductal gray of the cat. Brain Research, v.520, p.73-82, 1990. 